\title{
Polychlorinated biphenyls (PCBs) as sentinels for the elucidation of Arctic environmental change processes: a comprehensive review combined with ArcRisk project results
}

\author{
Pernilla Carlsson ${ }^{1}$ (D) $\cdot$ Knut Breivik $^{2} \cdot$ Eva Brorström-Lundén ${ }^{3} \cdot$ lan Cousins ${ }^{4} \cdot$ Jesper Christensen $^{5} \cdot$ Joan O. Grimalt $^{6}$. \\ Crispin Halsall ${ }^{7}$. Roland Kallenborn ${ }^{8,9} \cdot$ Khaled Abass $^{10,11} \cdot$ Gerhard Lammel $^{12,13}$. John Munthe ${ }^{3}$. \\ Matthew MacLeod ${ }^{4}$. Jon Øyvind Odland ${ }^{14}$ • Janet Pawlak ${ }^{15}$ • Arja Rautio ${ }^{11}$ • Lars-Otto Reiersen ${ }^{15}$ - Martin Schlabach ${ }^{2}$. \\ Irene Stemmler ${ }^{12,16}$. Simon Wilson ${ }^{15} \cdot$ Henry Wöhrnschimmel ${ }^{17,18}$
}

Received: 3 January 2018 / Accepted: 20 June 2018 / Published online: 28 June 2018

(C) The Author(s) 2018

\begin{abstract}
Polychlorinated biphenyls (PCBs) can be used as chemical sentinels for the assessment of anthropogenic influences on Arctic environmental change. We present an overview of studies on PCBs in the Arctic and combine these with the findings from ArcRisk - a major European Union-funded project aimed at examining the effects of climate change on the transport of contaminants to and their behaviour of in the Arctic - to provide a case study on the behaviour and impact of PCBs over time in the Arctic. PCBs in the Arctic have shown declining trends in the environment over the last few decades. Atmospheric long-range transport from secondary and primary sources is the major input of PCBs to the Arctic region. Modelling of the atmospheric PCB composition and behaviour showed some increases in environmental concentrations in a warmer Arctic, but the general decline in PCB levels is still the most prominent feature. 'Within-Arctic' processing of PCBs will be affected by climate change-related processes such as changing wet deposition. These in turn will influence biological exposure and uptake of PCBs. The pan-Arctic rivers draining large Arctic/sub-Arctic catchments provide a significant source of PCBs to the Arctic Ocean, although changes in hydrology/sediment transport combined with a changing marine environment remain areas of uncertainty with regard to PCB fate. Indirect effects of climate change on human exposure, such as a changing diet will influence and possibly reduce PCB exposure for indigenous peoples. Body burdens of PCBs have declined since the 1980s and are predicted to decline further.
\end{abstract}

Keywords Polychlorinated biphenyls $\cdot$ PCB $\cdot$ Arctic $\cdot$ Climate change $\cdot$ Environmental properties $\cdot$ Distribution pathways Environmental fate

\section{Background}

The Arctic environment and ecosystems are changing. For example, the Arctic cryosphere - the major feature of the ma-

This publication is dedicated to the memory of Prof. Eric Dewailly, one of the key Arctic Pollution Researchers, who dedicated his entire scientific career to Arctic pollution research and exposure risks of the Arctic indigenous peoples.

Responsible editor: Philippe Garrigues

Pernilla Carlsson

pernilla.carlsson@niva.no

Extended author information available on the last page of the article rine and terrestrial Arctic - is undergoing considerable change (Olsen et al. 2011) with the marine ice cover during the Arctic summer recently reaching a record minimum extent in 2012 (AMAP 2017). As a result, the ice-associated ecosystems in the Arctic are under increasing pressure (Grannas et al. 2013). The marine pelagic and benthic food webs are changing and new invasive species are competing with native Arctic species for food sources (Renaud et al. 2012). Fish stocks previously observed exclusively in lower latitude waters are moving into the Arctic marine environment for spawning (Kallenborn et al. 2012). These significant environmental changes are also expected to influence directly or indirectly the distribution patterns and fate of persistent organic pollutants (POPs) in the Arctic environment (AMAP 2003; AMAP 2011; UNEP/ AMAP 2011; Kallenborn et al. 2012; Macdonald and 
Bewers 1996; Macdonald et al. 2003; Macdonald et al. 2005; Pucko et al. 2015).

POPs are among the most investigated anthropogenic pollutants in the global environment. Their impact and hazardous effects on biotic and abiotic structures of the world's ecosystems have been documented in thousands of scientific studies and reports, and the risks of POPs have been well known for half a century already (Baldassare and Nicolle 1989; Ballschmiter and Zell 1980; Bowes and Jonkel 1972; Bright et al. 1995; Carpenter 1998; Jensen et al. 1969; Jones 1988; Lang 1992; McKinney and Waller 1994; Tanabe et al. 1983; Zitko and Choi 1972). Several early temporal trend studies revealed that Northern ecosystems have been exposed to POPs since the 1960-1970s (Bignert et al. 1998; Braune et al. 2001; Braune and Simon 2003). In the 1980s, combined field and modelling studies confirmed that semi-volatile POPs are transported into the Arctic via a combination of oceanic and atmospheric transport pathways (Barrie et al. 1992; Bidleman 1988; Wania and Mackay 1993, 1995, 1996). The strong bioaccumulation potential of these pollutants, to which Arctic food webs had already been exposed for several decades, leads to documented high POP concentrations in lipid tissues of Arctic marine mammals (Braune et al. 2005; Hickie et al. 2005; Ikonomou and Addison 2008; Kucklick et al. 2002). Marine mammals are the major traditional food source for indigenous Arctic peoples who rely on the availability and high nutritional values of this meat (Sharma 2010). Consequently, from some of the first studies examining POPs in humans living in the Arctic, elevated POP levels were identified in Canadian and Greenlandic Inuit living according to their traditional culture, which includes seasonal hunting of marine mammals (Bonefeld-Jørgensen 2010; BonefeldJørgensen and Long 2010; Dewailly et al. 1989; Dewailly et al. 1994; Hansen 1998; Van Oostdam et al. 2004). An early alarm signal of elevated polychlorinated biphenyl (PCB) levels in the Arctic environment published by Dewailly et al. in Dewailly et al. 1989 alerted Arctic governments to the presence of long-range transported contaminants in the Arctic. This led to the eight Arctic countries (Denmark, Iceland, Sweden, Norway, Finland, Russia, Canada and the USA) adopting the Arctic Environmental Protection Strategy and established the Arctic Monitoring and Assessment Programme (AMAP) to implement this strategy. AMAP was established as a working group under the Arctic Council (http://www.amap.no) in 1996 and has a circum-Arctic pollutant monitoring programme that includes more than 25 years of contaminant monitoring data in all Arctic environmental matrices. Because of their initiation and support of continuous monitoring and assessment activities, AMAP is today considered an important contributor to shaping the global and regional regulation of POPs within the European Union, under the UNEP Stockholm Convention on POPs and the Hemispheric Transport of Air Pollutants (HTAP) Aarhus Protocol, as well as by many national regulatory bodies. Based on the scientific evidence of their potential to pose a risk to human health and the environment in areas remote from sources, the production of legacy POPs and their usage is now globally regulated under the UNEP (Stockholm) Convention for the Protection of Human Health and the Environment from POPs. However, due to rapid developments and advancements in the technologies applied for pollutant analysis and toxicology, as well as ongoing risk assessments, new or 'emerging' organic contaminants are continuously identified and added to priority lists for international POPs monitoring (Fang et al. 2015; Magulova and Priceputu 2016).

\section{Scientific motivation}

Arctic long-term monitoring of pollutants, including PCBs, dates back as far as 40 years for some environmental compartments and cover periods with less rapid environmental changes compared to today (Bonefeld-Jørgensen 2010; Hansen et al. 2002; Heidam et al. 2004; Hung et al. 2010). Changes in Arctic environmental conditions are now rapid and dynamic (Macdonald et al. 2003; Olsen et al. 2011; Parkinson and Berner 2009; Wöhrnschimmel et al. 2013). Therefore, changes in chemical distribution profiles, uptake rates and degradation pathways may serve as early warning indicators for direct and/or indirect effects of the currently observed Arctic environmental changes on the presence and impact of POPs in the Arctic. Knowing this, and having access to several long-term studies from large circum-Arctic studies, a group of international scientists led by AMAP undertook a comprehensive European research initiative under the European Union's 7th Research and Innovation funding programme (FP7) entitled: 'Arctic Health Risks: Impacts on health in the Arctic and Europe owing to climate-induced changes in contaminant cycling' (ArcRisk).

This review highlights the interdisciplinary research and key findings of ArcRisk on climate-induced changes of POP cycling in the Arctic environment using PCBs as a useful example. PCBs were included among the group of pollutants that was intensively studied in the ArcRisk project and are among the most well-investigated POPs worldwide (Olsson et al. 2010). Furthermore, PCBs are probably the bestunderstood POPs group in terms of physical-chemical properties, emissions, pathways and observed concentrations in the global environment (Beyer and Biziuk 2009; Carpenter 2006; Faroon and Ruiz 2015; Fernandez-Gonzalez et al. 2015; Henry 2015; Korrick and Sagiv 2008; Peakall 1972; Ross 2004; Safe 1994). Therefore, they were chosen as a case study performed within ArcRisk for evaluating the performance of environmental fate and distribution models and as a benchmark for other POP-like substances in a set of climate change scenarios. Even though PCBs are banned, they are still present 
in large quantities in urban environments as well as the environment and they will remain so for at least another century (Kallenborn et al. 2012). In addition, evidence for new PCB sources that have the potential to contribute to Arctic environmental pollution have been presented recently (Bogdal et al. 2014; Diamond et al. 2010; Gasic et al. 2010; Hu and Hornbuckle 2010; Pedersen et al. 2011; Vorkamp 2016). PCBs comprise of a total of 209 separate congeners and are therefore discussed in this review as total PCBs, as the sum of different (but environmentally abundant) congeners (mainly the ICES PCB 7 congeners; PCB-28, 52, 99, 101, 118, 153 and 180) and as individual congeners, depending on available data. This paper is based on internal, unpublished reports from the ArcRisk project and on results from peer-reviewed papers within the project. The aim is to provide an overview of the research conducted within the ArcRisk project as a whole and combining results from all scientific areas including modelling, empirical investigations and meta-analysis of human health related to PCB. The present review begins with overviews of emissions of PCBs and their transport to the Arctic, followed by their environmental distribution and, finally, the impact that PCBs have on people living in the Arctic. Where possible, the aspect of climate change on the fate of PCBs in the Arctic is taken into account.

\section{Current PCB emissions and pathways to the Arctic}

\section{Emission estimates}

PCBs were used extensively during the 1950 s to 1970 s, mostly in industrial applications (such as coolants and insulating fluids) and as additives and sealants in building materials. After the 1970s, the production and use of PCBs were gradually restricted in many countries, and global emissions started to decrease. However, the decline in emissions lags strongly behind the rate of phase-out of production, because stocks of products in-use and materials continue to release PCBs to the atmosphere throughout their lifetime. Waste dumps, decommissioning sites as well as in-use stocks represent primary sources of today (Bogdal et al. 2014; Diamond et al. 2010; Gasic et al. 2010).

Furthermore, PCBs that have accumulated in the abiotic environment (sediment, water, soil, snow and ice) can be remobilized and thereafter re-emitted and thus may contribute to a slower declining rate of PCBs in the global atmosphere. Re-emissions from secondary sources will eventually become more important than primary sources in a global long-term perspective (Armitage et al. 2011; Stemmler and Lammel 2012). Recent review on fate and distribution of PCBs in the Arctic confirms these model-based results with empirical information (Hung et al. 2012; Kallenborn et al. 2012; Muir and de Wit 2010; Sobek and Gustafsson 2014; Villa et al. 2017; Vorkamp and Riget 2014).

In the modelling studies considered and applied in the ArcRisk project, the high-end emission scenarios for PCB28 and PCB153 estimated by Breivik et al. (Breivik et al. 2007) were used (Fig. 1), and the annual emission values were translated into monthly releases. It is important to note that the global emission inventory aimed at quantifying the 'big picture' in terms of global historical releases to air. The inventory may not accurately reflect actual emissions of a specific congener at a specific location or time. Local sources, still present within the Arctic, such as waste dumps, industrial installations and old settlements, may thus not be accurately represented in the global emission scenarios. Recent studies have shown the impact of these sources on the local environment on, e.g. Svalbard (Pedersen et al. 2011).

Nevertheless, atmospheric long-range transport is still considered to be a major route for the global environmental distribution of PCBs into remote areas. Even today, transport of contaminated air masses to the Arctic still occurs from regions in industrialised countries, where PCBs are still emitted from various sources (Hung et al. 2016). In spite of limited historical production and use of these chemicals, surprisingly high concentrations of PCBs were recently reported in some developing countries, partly attributed to transboundary export followed by poorly regulated recycling and disposal of relevant wastes (Bogdal et al. 2014; Breivik et al. 2011; Gasic et al. 2010; Hung et al. 2016; MacLeod et al. 2014).

\section{Spatial variations of PCB concentrations in the Arctic}

An overview of atmospheric concentrations of $\sum_{7} \mathrm{PCBs}$ at different sites in European and Arctic areas is available from www.genasis.cz and www.pops-gmp.org where additional information can be found (including other compound groups). Based on this comprehensive data, the highest atmospheric concentrations of $\mathrm{PCB}_{7}$ are present in central and eastern Europe where levels higher than $500 \mathrm{pg} / \mathrm{m}^{3}$ can occur and indicate the presence of 'hot spots' areas. The highest PCB levels at background sites were also found in central and eastern Europe (Halse et al. 2011). The concentrations in Arctic areas are generally in the range $<5-30 \mathrm{pg} / \mathrm{m}^{3}$ (Hung et al. 2010, 2016).

Levels and long-term time trends of PCBs and other POPs are monitored on a continuous basis in the Arctic atmosphere within different national monitoring programmes. The Arctic sampling sites and the European reference sampling sites used within the ArcRisk project are shown in Fig. 2. The air monitoring at these stations has been carried out since the early 1990s and quality-controlled data are continuously reported to the AMAP and the European Monitoring and Evaluation Programme (EMEP) programmes (Hung et al. 2016; Tørseth et al. 2012). 
Fig. 1 Global primary emissions scenarios of PCB28 and PCB153 to air (high-end estimate), according to Breivik et al. (2007)
PCB emissions (tons/year)

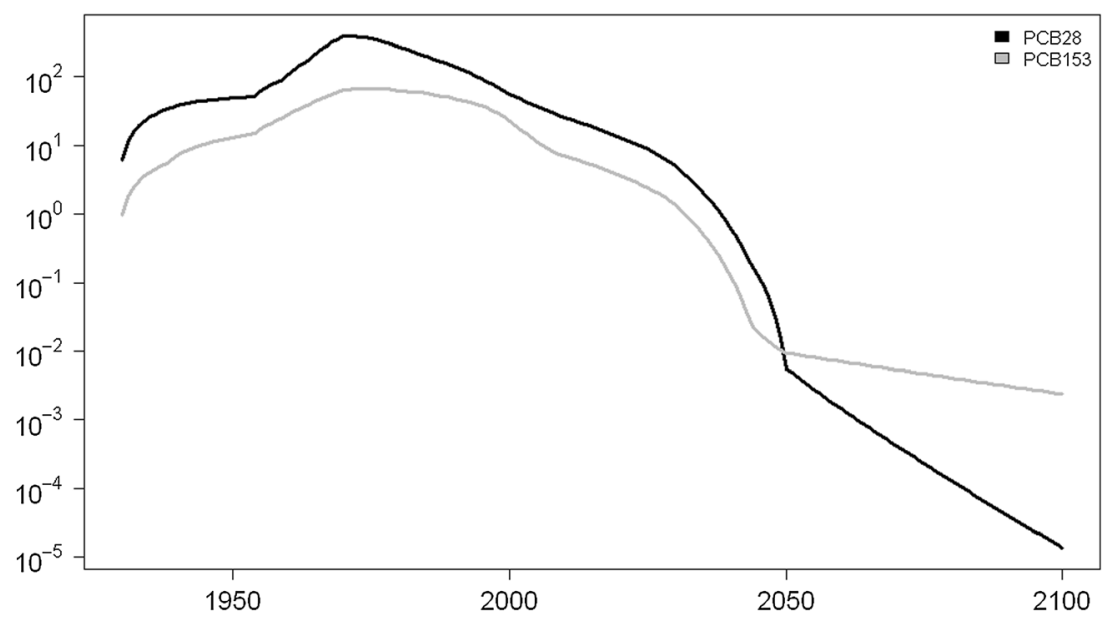

The average PCB concentrations at the four major Arctic atmospheric monitoring sites of Alert (Canada), Pallas (Finland), Stórhöfði (Iceland) and Zeppelin (Svalbard/ Norway) may vary due their proximity to sources and sources and their geographical location (latitude and longitude) but also due to environmental factors such as marine or continental influence, altitude and the prevailing meteorology for the respective stations (e.g. see Hung et al. 2010, 2016).
The yearly average atmospheric concentrations of $\mathrm{PCB}_{7}$ at the high Arctic stations (Alert; northeast Canada and Zeppelin; Svalbard) and the European sub-Arctic stations (Stórhöfði; Iceland and Pallas; northern Finland 60-66 N) in 2009 are shown in Fig. 3, where also the PCB concentrations from background sites in central Europe (Košetice in the Czech Republic) and southern Scandinavia (Råö, at the Swedish west coast) are shown. An obvious decrease in the
Fig. 2 Long-term monitoring stations for PCBs and other air pollutants. Red dots indicate Arctic stations and blue dots indicate European stations included in ArcRisk. Pallas and Zeppelin were directly included and used in the ArcRisk project for sampling in the Arctic. Data from the other Arctic stations was incorporated, but no own sampling campaigns were launched there

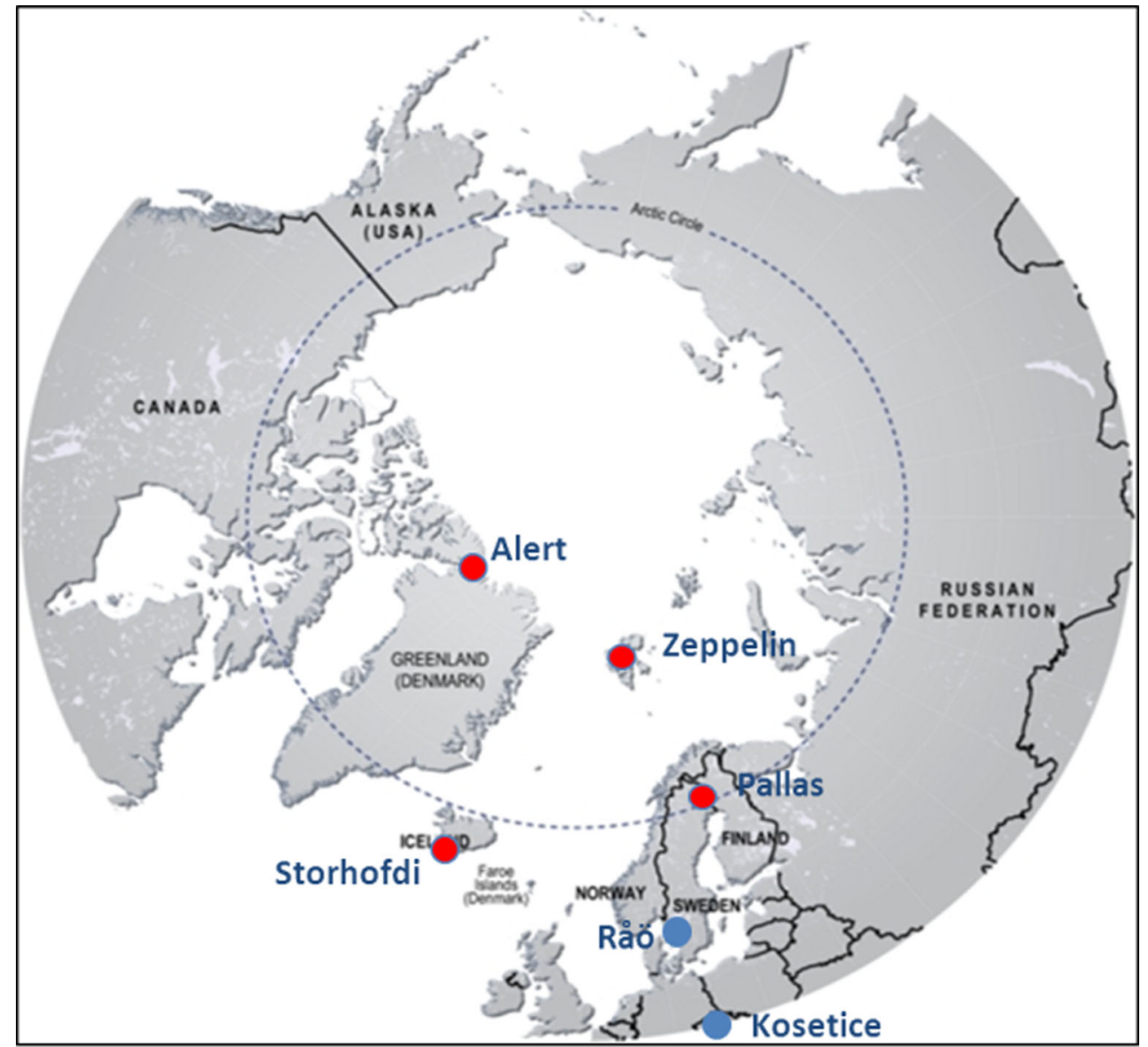


Fig. 3 Yearly average atmospheric concentrations in 2009 of $\Sigma_{7}$ PCBs $(28,52,101$, $118,138,153,180$ ) (please note that PCB138 is not included at Alert)

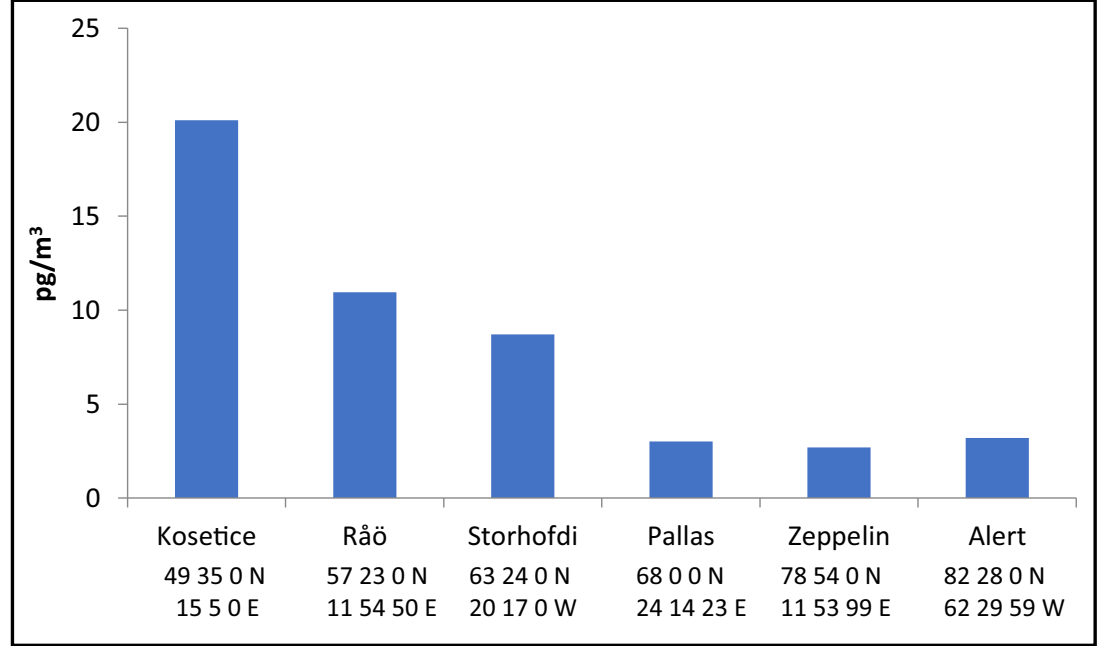

PCB concentrations from central Europe and southern Scandinavia to the Arctic areas is evident. The PCB concentrations at Stórhöfði were comparable to levels in southern Scandinavia (Råö) and the concentrations at Pallas were at the same level as those at the high Arctic stations (Hung et al. 2010, 2016).

During 2009, the concentrations of PCBs at the Arctic stations, Zeppelin (east) and Alert (west) were at the same level, in contrast to the period 1993 to 2006 for which Hung et al. (2016) reported a west-east gradient, the eastern stations being characterised by higher PCB levels.

\section{Time trends and seasonal cycling in atmospheric PCB patterns}

Long-term trends and seasonal cycles of PCBs at different Arctic atmospheric monitoring stations may reveal the influence of regional, local and seasonal factors and are thus expected to give essential information to assess the effectiveness of control strategies. The ArcRisk work builds on extensive time series of POPs in the Arctic. Results from these time series are presented in this chapter, including results that have not been published elsewhere.

The atmospheric PCB concentrations in the Arctic have shown a continuous decreasing trend over the past decades, after the international regulation of $\mathrm{PCB}$ production and usage was enforced (Hung et al. 2016). Hung et al. (2016) showed a general decline in the concentrations at Pallas, Alert and Zeppelin over the period 1998-2012. Declining PCB concentrations have also been identified at Pallas for the period 1996-2008 (about 3\%/year for $\sum_{7} \mathrm{PCB}$ ), which was similar to the decline observed in southern Scandinavia earlier (Backe et al. 2002). The yearly average atmospheric concentrations of PCB28 (tri-CB) and PCB153 (hexa-CB) at Pallas, Alert and Zeppelin between 1997 and 2009 are shown in Fig. 4. Further details on more comprehensive Arctic atmospheric monitoring can be found elsewhere (AMAP 2016; Hung et al. 2016).

The concentrations of both PCB28 (tri-CB) and PCB153 (hexa-CB) were generally higher at Zeppelin in comparison to Pallas and Alert for several of the years, but the difference is levelling out. For the Zeppelin station, increasing trends for medium chlorinated (penta- to hexa-chlorinated CBs) were reported in the period 2004 to 2009 (decreasing PCB levels after 2009). Occasionally elevated levels during this period were associated with biomass burning events in Eastern Europe and boreal forest fires in North America, followed by transport of contaminated air into the Svalbard region, which may be seen in the context of a changing climate in the boreal region (Eckhardt et al. 2007; Kelly et al. 2013). Reemission of (lighter) PCBs from oceans and snow caps might also contribute to increasing PCB concentrations in the Arctic atmosphere (Hung et al. 2016). Pallas showed a similar trend as Zeppelin, with increasing concentrations until 2006 followed by a decreasing trend thereafter. Modelling explained why the concentration of pollutants in the atmosphere above Svalbard correlates with the Arctic Oscillation, whereas this is not the case above Greenland (Octaviani et al. 2015). The Arctic Oscillation is a regular oscillation of the atmosphere above the Arctic that creates differences in atmospheric pressure. Pollutant flows from Europe, which correlate positively with the Arctic Oscillation, maintain the concentrations above Svalbard. The pollutant concentrations above Greenland, however, are determined by flows in the Canadian Archipelago, where air currents are in a reverse relation with this oscillation.

\section{Atmospheric deposition pathways}

Deposition from the atmosphere (both wet and dry deposition) is the dominant process for the input of PCBs into both terrestrial and marine Arctic environments (Garmash et al. 2013; 
Fig. 4 Yearly average atmospheric concentrations of PCB28 and PCB153 at Pallas, Alert and Zeppelin
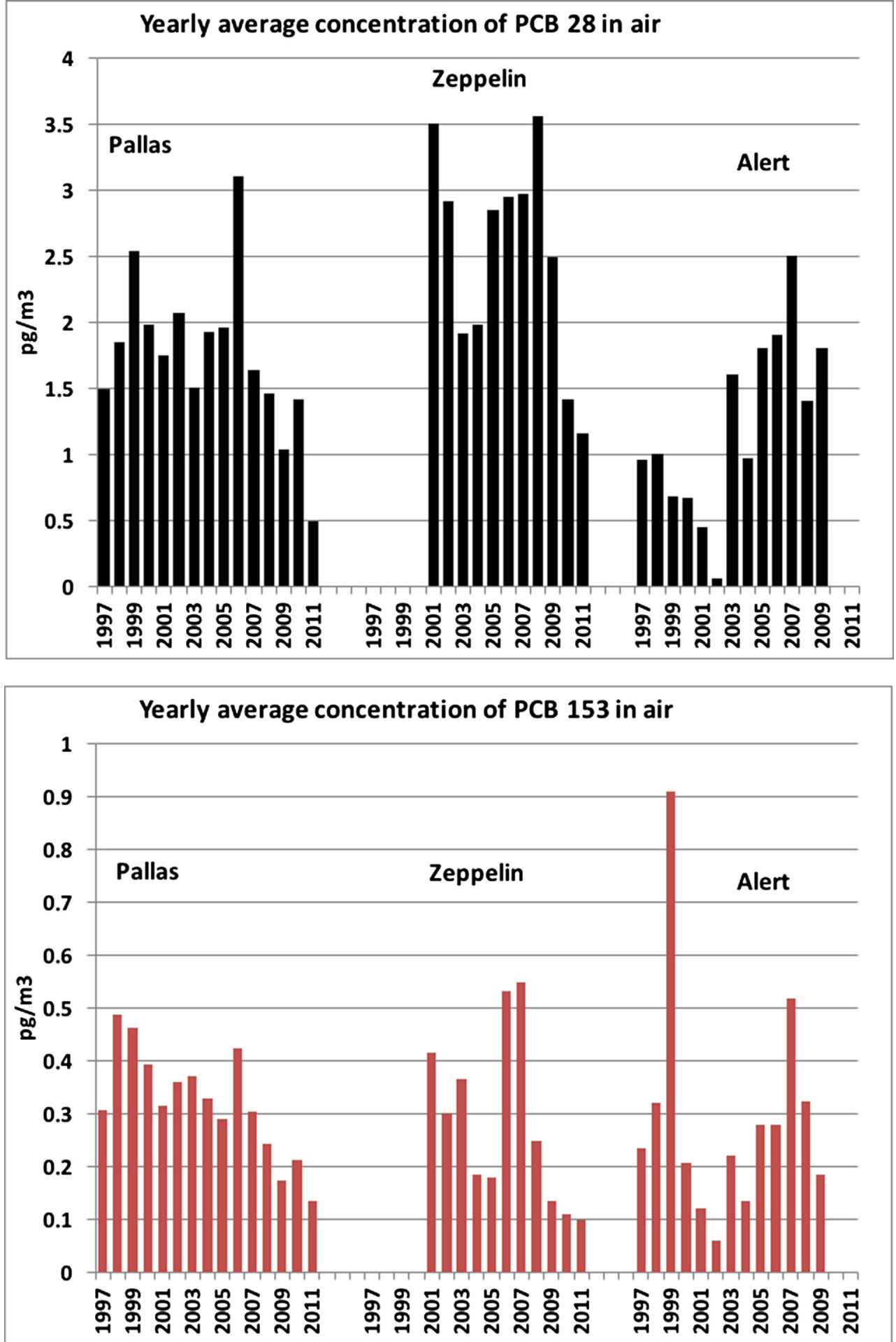

Kallenborn et al. 2007; Malmquist et al. 2003). At Pallas, long-term deposition measurements of PCBs have been carried out since 1997. The results from these measurements are shown in Fig. 5 where the deposition fluxes from Råö at the Swedish west coast are included as comparison. Deposition data from long-term monitoring in the high Arctic are not available.
The annual average deposition fluxes of the $\Sigma_{7}$ PCBs at Pallas ranged from 100 to $300 \mathrm{ng} / \mathrm{m}^{2} /$ year in the period 1997-2010. The deposition fluxes at Pallas are about twofold lower than those measured in southern Scandinavia. The highest deposition fluxes occurred during the first measurement years and the lowest, like the air concentrations, during recent years. However, unlike 
Fig. 5 Yearly atmospheric deposition fluxes of $\Sigma_{7}$ PCBs (28, $52,101,118,138,153,180)$ at Råö and Pallas (bulk deposition) as reported in the final ArcRisk report (www.arcrisk.eu)

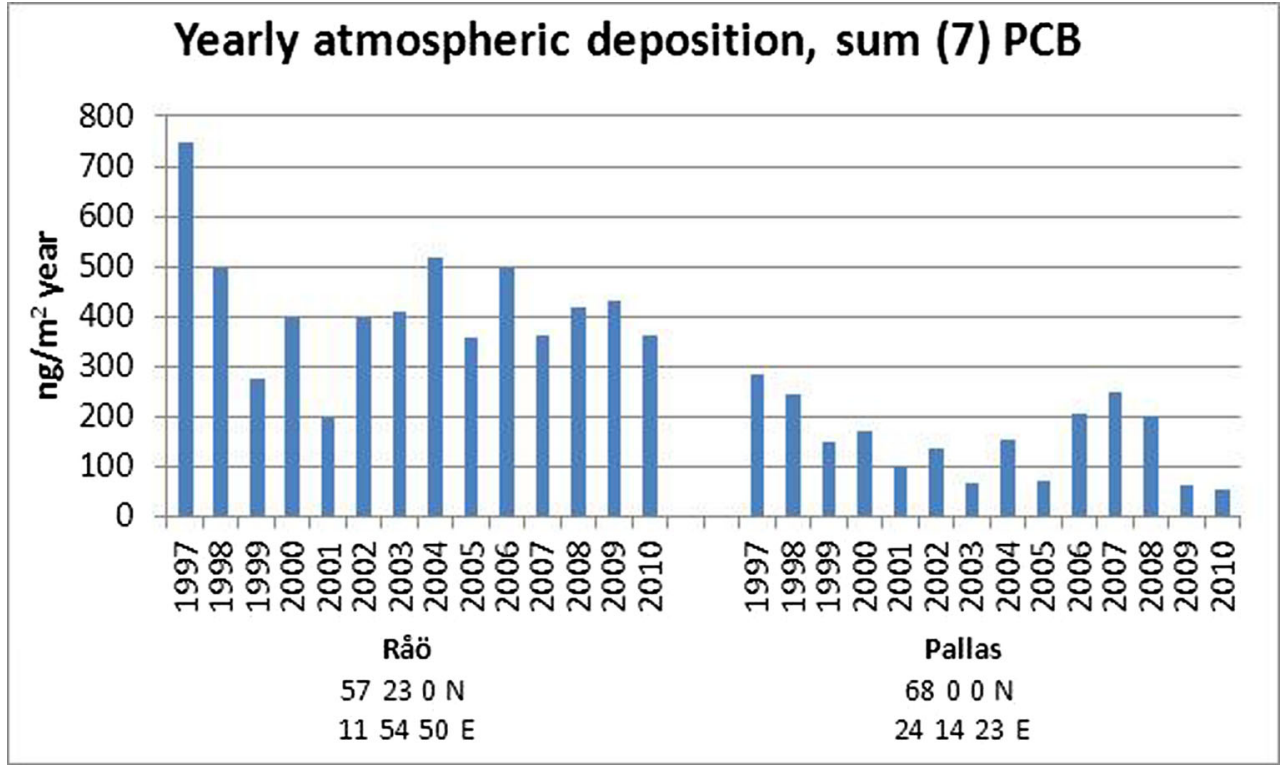

for PCB concentrations in air, no decreasing trend was observed (Fig. 5).

As the PCB levels in air at Pallas and Zeppelin (Hung et al. 2016) are reported in the same order of magnitude, we could assume that yearly deposition at Zeppelin should be considered in the same range as for Pallas. However, total atmospheric deposition fluxes are dependent not only on gaseous and particulate phase concentrations but also on precipitation type and rate, ambient temperature and atmospheric particulate matter concentration and mass size distribution (see also discussion on PCBs in snowpack in section 'Emission estimates'). Wet deposition at colder temperatures (e.g. close to $0{ }^{\circ} \mathrm{C}$ ) is more efficient at scavenging semi-volatile organic chemicals such as PCBs from the atmosphere, compared to wet deposition at warmer temperatures (see Lei and Wania (2004)). The dominance of snowfall in annual precipitation at more northerly sites may account for the lack of a decline in observed deposition fluxes (Hansen et al. 2006; Hansson et al. 2006).

\section{Important inter-compartmental transfer processes in the Arctic}

\section{Processes and pathways in Arctic snow and ice}

The extensive usage history of PCBs (documented since the 1920s; Kimbrough and Jensen (1989)) until their global ban during the 1980s/1990s has resulted in their ubiquitous global distribution. Atmospheric and chemical processes drive transfer between environmental compartments in the Earth system including transfer to the Arctic, with these processes continuing long after PCBs have been phased out from usage. Atmospheric deposition to the extensive sub-Arctic catchment areas of the larger Arctic-draining rivers has provided considerable PCB loads to the rivers. In combination with point sources of PCBs located within these catchment areas, the rivers serve as important sources of PCBs to the Arctic regional seas (Carrizo and Gustafsson 2011b; Carroll et al. 2008; Rawn et al. 2001; Sobek and Gustafsson 2014). Atmospheric transport and deposition via snow fall have been identified as important transfer process in the Arctic including PCB deposition fluxes (Garmash et al. 2013; Hansen et al. 2006; Pavlova et al. 2014). Rapid redistribution processes during surface snow weathering determine whether the respective contaminant is re-evaporated, released into the soil or retained in the snowpack throughout the season (Herbert et al. 2005). However, the contribution of PCBs from melting snow and sea ice to the total PCB content in the Arctic marine environment is low compared to input from Arctic rivers. Nevertheless, rapid thawing processes and the changing Arctic marine cryosphere in a warmer Arctic could impact PCB exposure to ice-associated algae and fauna during the spring algal bloom (Carroll et al. 2008). However, deposition of PCBs with snowfall and subsequent accumulation in the seasonal snowpack, as well as accumulation in sea ice and colder Arctic waters, are still not sufficiently understood and quantified (Gustafsson et al. 2005; Hansen et al. 2006; Herbert et al. 2005).

Deposition processes and snow ice interactions of PCBs have been a research focus in the Canadian Arctic for many decades (Macdonal et al. 1996). A series of studies have been conducted to shed light on PCB accumulation and deposition in the Canadian Arctic. A winter field campaign in the Canadian Arctic measured PCBs in the surface snowpack from April through to early June 2008, just prior to ice breakup as part of a larger campaign to look at contaminant and nutrient flows associated with ice floes and associated ice 
leads (Pucko et al. 2015; Grannas et al. 2013). The mean concentration of $\sum_{29} \mathrm{PCB}$ in snow was $256 \pm 177 \mathrm{pg} / \mathrm{L}$, although two fresh snowfall layers sampled in May displayed higher concentrations of 545 and $611 \mathrm{pg} / \mathrm{L}$ (Codling 2012). Excluding these two events, the average concentration in the snowpack was $185 \pm 85 \mathrm{pg} / \mathrm{L}$, which is substantially higher than PCB concentrations in surface seawater, indicating the efficiency of the snowpack to scavenge and accumulate semivolatile organic chemicals from the overlying atmosphere. The PCB concentrations in the winter marine snowpack were lower than PCB concentrations measured previously in surface snow layers in northern Norway by a factor of $\sim 2-5$ (Herbert et al. 2005) but markedly higher (by 27-fold) than concentrations previously measured in ice-rafted snow collected in the marginal ice zone of the Barents Sea (Gustafsson et al. 2005) and distinctly higher than in Antarctica (Desideri et al. 1994; Vecchiato et al. 2015). The Barents Sea study was conducted during a Swedish research expedition in the marginal ice zone during July 2001, when the snow had already undergone substantial metamorphosis associated with repeated freeze-thaw cycles resulting in the likely loss of gaseous PCBs, either through volatilisation or re-partitioning to particulate matter. Interestingly, in the marginal ice zone, the particle-bound concentration was $99 \mathrm{pg} / \mathrm{L}$ (based on $\sum_{15} \mathrm{PCB}$ measured in a composite snow sample marked by high levels of particle organic carbon $(668 \pm$ $50 \mathrm{mg} \mathrm{POC} / \mathrm{g})$ ), while a mean concentration of $14.6 \pm$ $11.9 \mathrm{pg} / \mathrm{L}\left(\sum_{15} \mathrm{PCB}\right)$ of the particle-bound PCBs was measured. Thus, this earlier report indicates substantial reprocessing and loss of PCBs during ageing and partial melt of the marine snowpack.

During the more recent campaign in the Tromsø (North Norway) area, the vapour-sorbed PCB concentrations in the snowpack accounted for approximately $80 \%$ of the PCB burden with $\sim 20 \%$ associated with particles. Figure 6 illustrates the spring time series of PCB52 (tetra-chlorinated PCB) and PCB153/132 (hexa-chlorinated PCBs) in the marine snowpack in Beaufort Sea. Aside from the fresh snowfall event on 17 May, PCB52 concentrations in snow (white bars) declined over the time series notably once air temperatures started to exceed $0{ }^{\circ} \mathrm{C}$ (for part of each 24 -h period). The heavier PCB153/132 does not show this trend (BrorströmLundén et al. 2013). Losses of the lighter PCBs and, hence, enrichment of the heavier PCBs are due to volatilisation losses as the snowpack ages and can be attributed to changes in snow structure (specifically loss of snow surface area as the snow ages) (Stocker et al. 2007). To assess the role of the snowpack and first-year sea ice in supplying accumulated contaminants to the polar mixed layer of the Beaufort Sea, a late season snowpack and ice column inventory was calculated. The PCB congeners (AMAP '10'; PCB-28, 31, 52, 101, 105, $118,138,153,156$ and 180) were selected based on the chemical concentrations measured in the snowpack and sea ice, assuming full ice cover (and hence an ice-rafted snowpack) over the entire Beaufort Sea, prior to ice breakup in June. The $\sum_{10} \mathrm{PCB}$ burden in both snow and ice is presented in Table 1 and was estimated as $6.17 \pm 3.34 \mathrm{~kg}$ (Codling 2012). This value is similar to a recent estimate of the PCB inventory for the polar mixed surface layer of the Beaufort Sea of $4.47 \mathrm{~kg}$ (Carrizo and Gustafsson 2011a). However, in that study. a much smaller area of the Beaufort Sea was selected for the calculations $\left(178,000 \mathrm{~km}^{2}\right.$ and $124 \mathrm{~m}$ depth). When this area is used for ice cover instead, the PCB inventory for snow and ice becomes $\sim 2.5 \mathrm{~kg}$. Assuming minimal ice export from the Beaufort Sea, then the release of PCBs from the snow/ice system into surface seawater (i.e. the polar mixed layer $40 \mathrm{~m}$ depth) during final melt would yield concentrations in seawater of $\sim 0.16-0.53 \mathrm{pg} / \mathrm{L}$ or $\approx 5-18 \%$ of the $\mathrm{PCB}$ concentration present in surface waters of the Beaufort Sea. These values provide a first quantitative estimate for the role of the sea ice system in storing and releasing POPs to seawater along a seasonal temperature and cryosphere extension pattern (Carrizo and Gustafsson 2011b).

\section{Riverine transport as an Arctic distribution pathway}

The Arctic Ocean receives PCBs via deposition from the atmosphere, from drainage of the major Arctic-flowing rivers and through surface ocean currents entering the Arctic from the Atlantic and Pacific Oceans (Fig. 7). Pan-Arctic riverine fluxes of PCBs have been estimated based on recent shipbased campaigns that measured PCBs in the fluvial surface sediments in the estuaries of the six major Arctic-draining rivers (Ob, Yenisey, Lena, Indigirka, Kolyma and Mackenzie) and are currently seen as important PCB distribution pathways (Carrizo and Gustafsson 2011b; Carroll et al. 2008). Combined, these six rivers contribute on average $1935 \mathrm{~km}^{3} /$ year of freshwater discharge to the coastal seas of the Arctic Ocean, the largest proportion of freshwater flows to the Arctic Ocean. The $\Sigma_{13} \mathrm{PCB}$ fluxes (kg/year) are presented in Fig. 7. The highest PCB fluxes occurred for the two major Russian rivers, $\mathrm{Ob}$ and Lena - the rivers with the highest water discharge rates and with catchments that extend far to the south beyond the Arctic. The $\Sigma_{13} \mathrm{PCB}$ fluxes from these rivers were estimated to be $183 \mathrm{~kg} /$ year for $\mathrm{Ob}$ and $113 \mathrm{~kg} /$ year for Lena. As comparison, the Mackenzie and Yenisey rivers have $\Sigma_{13}$ PCB fluxes of 60 and $45 \mathrm{~kg} /$ year, respectively, followed by the eastern Siberian rivers of the Kolyma and Indigirka, with fluxes of 10 and $3.9 \mathrm{~kg} /$ year, respectively. These fluxes are based on estimates made a decade ago, and with continuing climate-induced changes to the Arctic environment, it is likely that these fluxes will have changed. However, across these six rivers, the PCB congener composition differed, with the Russian rivers possessing relatively higher fractions of the penta- and hexa-chlorinated PCB congeners and the Mackenzie River (Canada) possessing higher fractions of the 
Fig. 6 Concentrations of PCB52 and PCB153/PCB132 in the icerafted snowpack of the Beaufort Sea (Arctic Canada) during the late winter season (April-June 2008) (Codling 2012)

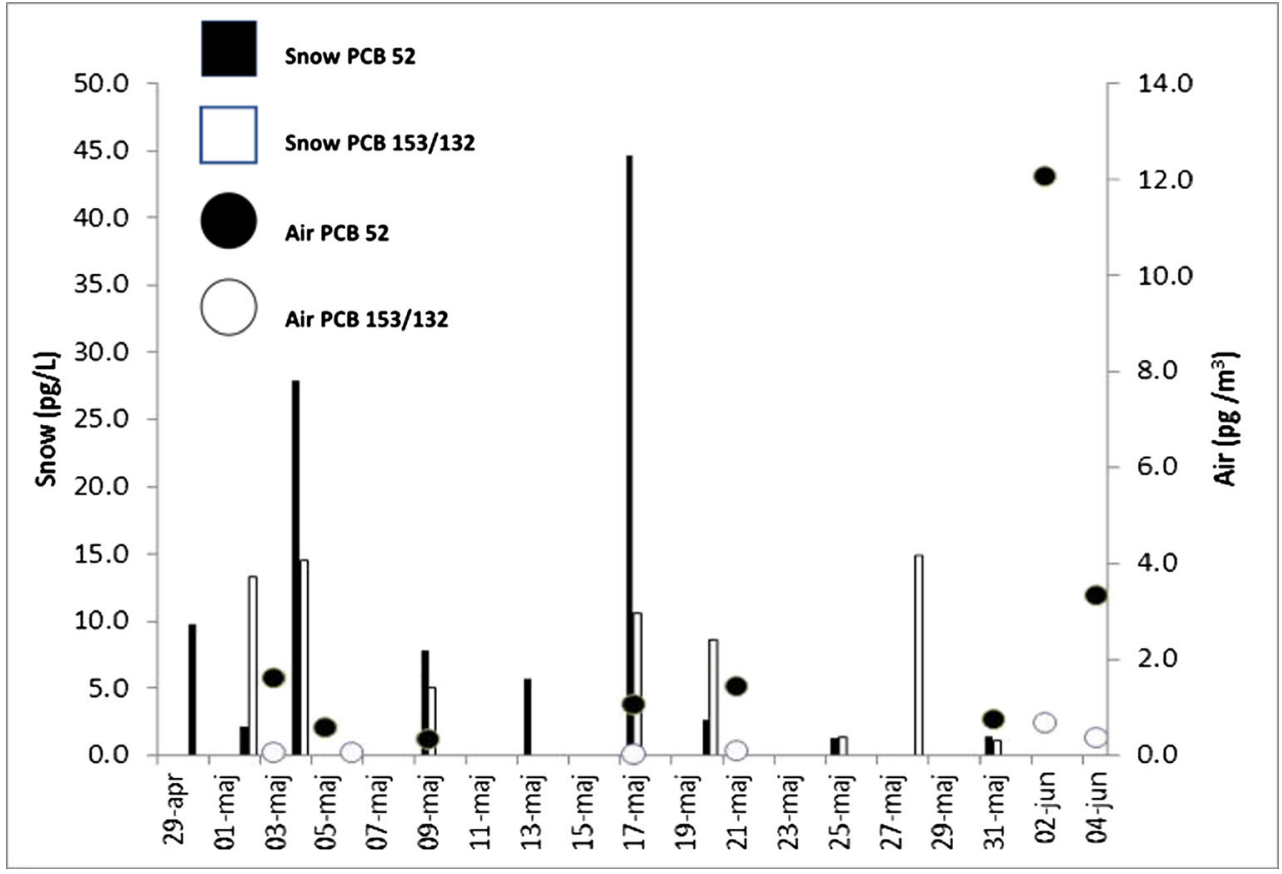

tri- and tetra-PCB congeners. This difference between the Russian and Canadian rivers is probably related to the major Russian technical PCB formulation of 'Sovol', which is composed of $\sim 50 \%$ penta-chlorinated congeners. In order to complement the riverine flux assessment of PCBs, a recent evaluation of PCB concentrations in the Arctic coastal seas has been undertaken (Carrizo and Gustafsson 2011a). This assessment included an examination of the PCB congener composition to understand the influence of different source regions on the Arctic and the mode of transport, e.g. atmospheric vs. transport in water.

Figure 8 illustrates the spatial distribution of surface seawater PCB concentrations for the different geographical regions. Contemporary PCB concentrations across the Arctic Ocean range from ( $\left.\Sigma_{13} \mathrm{PCB}\right) 0.13$ to $21 \mathrm{pg} / \mathrm{L}$, with higher concentrations in the shelf seas than in the central Arctic

Table 1 Estimated load (kg) of PCBs in the sea ice system of the entire Beaufort Sea prior to ice breakup

\begin{tabular}{lll}
\hline & Snowpack & Ice \\
\hline PCB18 & $0.45 \pm 0.21$ & $2.66 \pm 1.33$ \\
PCB31/28 & $1.87 \pm 0.96$ & $0.25 \pm 0.13$ \\
PCB52 & $0.13 \pm 0.05$ & $0.07 \pm 0.03$ \\
PCB99/101 & $0.29 \pm 0.20$ & $0.01 \pm 0.007$ \\
PCB118 & $0.03 \pm 0.04$ & $\mathrm{NR}$ \\
PCB153/132 & $0.22 \pm 0.16$ & $0.02 \pm 0.01$ \\
PCB138 & $0.17 \pm 0.22$ & $\mathrm{NR}$ \\
$\Sigma_{7}$ PCB & $3.16 \pm 1.84$ & $3.01 \pm 1.50$ \\
\hline
\end{tabular}

Data from Codling (2012)

$N R$ not reported
Ocean. Tri-chlorinated PCBs contribute about $50 \%$ of the total PCB loading in the surface waters of the eastern Arctic (Bering, Chukchi and Beaufort seas), suggesting a predominantly atmospheric source, whereas the hexa-chlorinated PCBs are more abundant in the western part of the Arctic (Barents and Greenland seas), suggesting the influence of waterborne transport from regions with previous heavy PCB usage such as northern Europe and North America.

The first Pan-Arctic assessment by Carrizo and Gustafsson provided a comprehensive overview of PCBs in marine surface waters, including a baseline to model the uptake of PCBs into the marine food webs and also the basis to forecast future changes in PCB exposure for different regions of the Arctic (Carrizo and Gustafsson 2011a, b).

\section{Arctic soils}

The terrestrial environment has been shown to be of importance for global POP cycling, and soils and forests in the northern hemisphere are recognised as storage compartments with a large capacity for POPs such as PCBs (Meijer et al. 2003; Kallenborn et al. 2012). We applied a global modelling using a multi-compartment chemistry-transport model for the decade 2001-2010 (Stemmler and Lammel 2012). This model forecast that high-chlorinated PCBs such as PCB153 will increase with $0.6 \%$ year in Arctic soils, despite decreasing primary emissions (since the 1970s) and unlike in other regions. This feature was not shown for the low-chlorinated congeners. In comparison to mid-latitudes, the low-medium chlorinated congeners are enriched in the polar atmosphere as well as in ground compartments. These results indicate the strong 


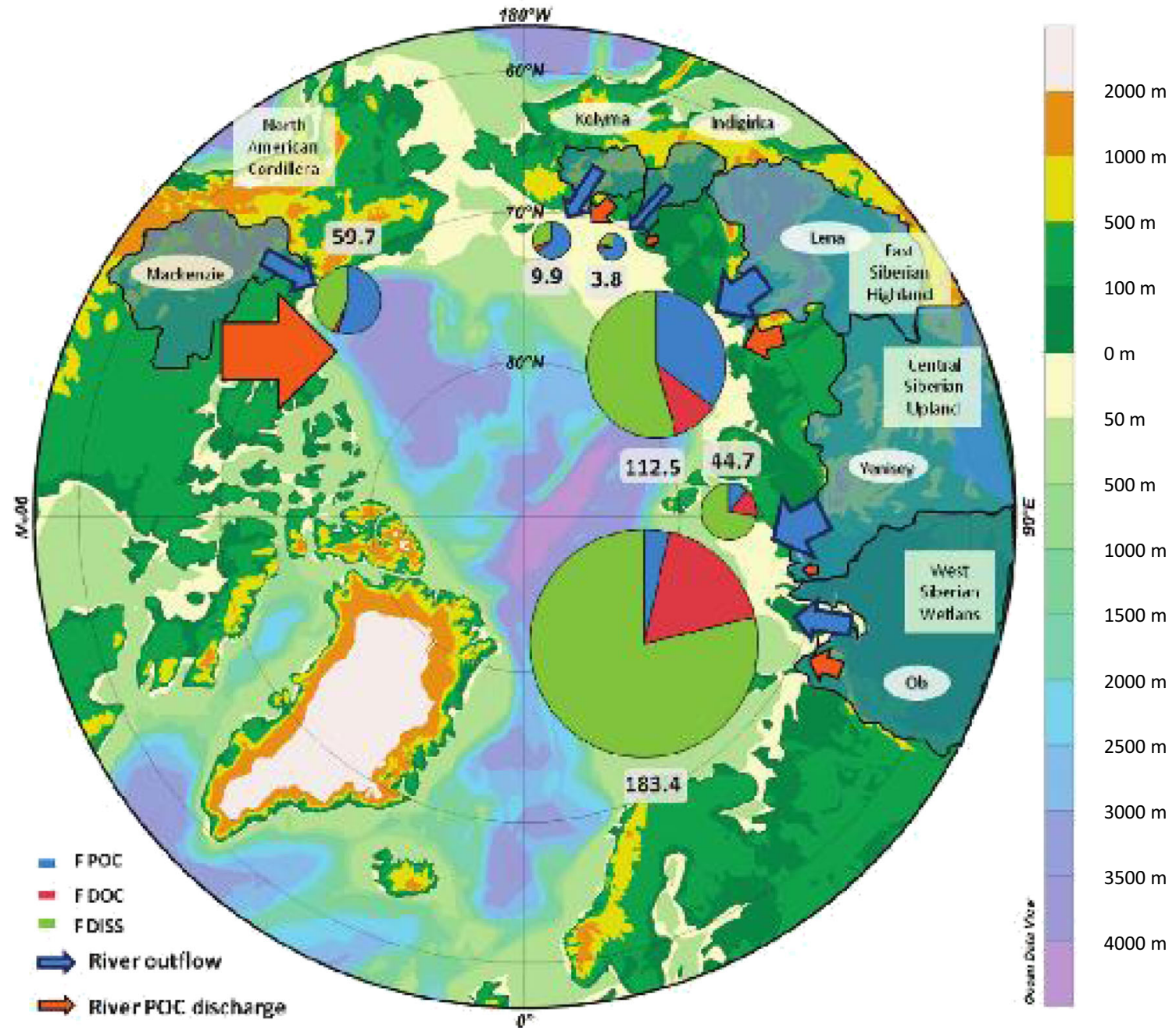

Fig. $7 \Sigma_{13}$ PCB fluxes (kg/year) estimated for the six major Arctic rivers are given for the dissolved (F DISS), DOC-associated (F DOC) and particulateassociated (F POC) fractions. Please note the figure is reproduced from Carrizo and Gustafsson (2011b)

significance of secondary sources for the cycling and subsequent accumulation of these contaminants in polar ecosystems.

\section{PCB occurrence in biota and trends in the Arctic}

PCBs have been measured in a number of biological matrices in the Arctic environment. A west-to-east gradient for PCB levels has been identified, with the highest levels occurring in the Eastern Arctic (Hobbs et al. 2003; Muir et al. 1992; Norstrom et al. 1998; Verreault et al. 2005). In particular, Arctic top-predator animals have accumulated considerable PCB burdens in their lipid tissues (Bjerregaard-Olesen et al. 2017; Bustnes et al. 2017; Dallaire et al. 2013; Nost et al. 2017; Pedro et al. 2017a; Ryan et al. 2013); AMAP 2016). During the past decade, several review papers have summarised information about the distribution patterns and ecotoxicology of PCBs in the Arctic (Derocher et al. 2003; Fisk et al. 2005; Letcher et al. 2010; Sagerup et al. 2009; Tartu et al. 2014; Tartu et al. 2015; Toft 2014; Verreault et al. 2006; Vijayan et al. 2006).

As documented in national and circum-Arctic monitoring (Hung et al. 2016; Letcher et al. 2010; Muir and de Wit 2010; Olsen et al. 2011), PCB concentrations in many environmental compartments, including biota, have continuously decreased over recent decades. Riget et al. (2010) studied time trends of PCBs in Arctic biota: fish, seabirds, marine mammals and reindeer. They found a decrease in the annual mean concentrations per year of 1.2 and $1.9 \%$ for PCB153 and $\sum_{10} \mathrm{PCB}$, respectively. The authors used 40 (PCB153) and $16\left(\sum_{10} \mathrm{PCB}\right)$ time series covering at least 6 years for samples collected in Canada, Iceland, Greenland, Norway and Sweden. Around $40 \%$ of those time series showed statistically significant decreasing trends across the Arctic area. However, in a few cases, a statistically significant increase in concentrations was seen (blue mussels, Iceland; freshwater fish, Canada; marine mammal population, Faroe Islands) in those trend studies (AMAP 2016 (Riget et al. 2010). 


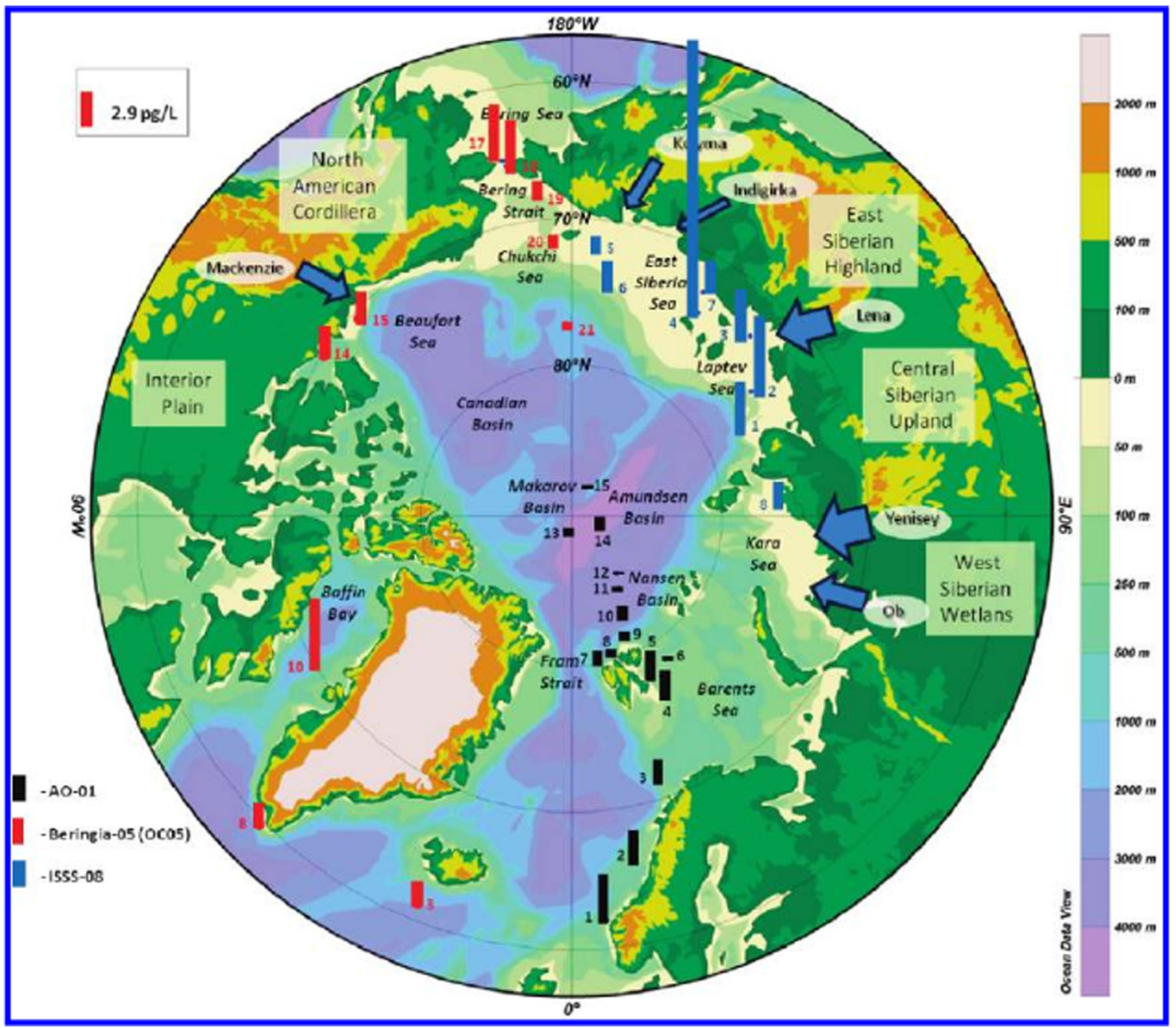

Fig. $8 \quad \Sigma_{13} \mathrm{PCB}$ concentrations (pg/L) (dissolved and particle-bound) in the surface waters (polar mixed layer) of the Arctic Ocean. The colour key indicates the research campaign; the numbers on the bars are station numbers. The concentration key is at the upper left. Please note the figure is reproduced from Carrizo and Gustafsson (2011b)

A short overview of PCB distribution in biota and its consequences in the Arctic environment, based on the work conducted within ArcRisk, is presented here.

\section{Levels in Arctic biota}

A variety of earlier trend studies are reporting data from North Atlantic cod (Gadus morhua) in the Arctic (Ballschmiter and Zell 1980; Cleemann et al. 2000; Foreid et al. 2000; Haukas et al. 2007; Hellou et al. 1993; Pedro et al. 2017b; Sturludottir et al. 2014). Letcher et al. (2010) reviewed $\sum$ PCB concentrations in mammals in the Arctic and found that lipid-normalised concentrations (lw) in tissues from whale species varied between 451 and 230,000 ng/g lw. In ringed seal, the mean PCB concentrations in blubber ranged between 200 and $1370 \mathrm{ng} / \mathrm{g} \mathrm{lw}$ and the blood concentrations in Stellar sea lions between 3692 and $18,000 \mathrm{ng} / \mathrm{g}$ lw. Polar bears had PCB concentrations in fat varying between 1138 and $9100 \mathrm{ng} / \mathrm{g}$ lw. Long-term time series of PCBs in Arctic marine mammals are, in general, decreasing, although there are exceptions that can be linked to changes in diet or changes in environmental processes that impact run-off and re-emissions (McKinney et al. 2011); AMAP 2016).

In the ArcRisk project, several Arctic food products from Nuuk, Greenland were analysed for PCBs and other POPs (Carlsson et al. 2014a). ArcRisk results showed that food products derived from marine mammal species are contaminated with a variety of organic contaminants, such as a suite of perfluorinated alkylated substances (PFAS) as well as conventional legacy POPs that have been included in the Stockholm Convention for over a decade, such as PCBs. Not surprisingly, the highest PCB concentrations were found in narwhal mattak (skin and blubber), with a median concentration of $1147 \mathrm{ng} / \mathrm{g}$ lw. As a comparison, median concentrations of $\sum$ PCB in seal meat and salmon were 302 and 227 ng/g lw, respectively. All samples were collected in the local food market in Nuuk, Greenland. The congeners PCB153 and - 138 were dominant (30\% of the total PCB concentrations) in all samples investigated and even contributed $52 \%$ of the PCB load in the seal 
meat. PCB153, PCB138, PCB118 and PCB101 together contributed more than $50 \%$ of $\triangle \mathrm{PCB}$ in all samples. The relative contributions of PCB118 and PCB153 were slightly higher in fresh salmon compared to smoked salmon, while the relative contributions of PCB101 and PCB149 were slightly higher in the smoked salmon. This indicates some influence of food processing on PCB profiles, although other congeners with a large relative contribution did not differ much (Carlsson et al. 2014a). The PCB levels (ng/g lw) in Greenlandic fish products found in this study are comparable to levels found in other studies from Arctic areas and to PCB levels in fish from European sites. As a follow-up to this study, a current report on shrimp and Northern halibut filet from Northern Norway confirmed the still prominent role of PCBs in the contaminant profile of marine species commercially exploited as seafood in the North (Carlsson et al. 2016).

The levels of $\Sigma \mathrm{PCB}$ in the smoked halibut from the Arctic were in line with levels in halibut from Tromsø (Carlsson et al. 2016) and Greenland (Johansen et al. 2004). However, the levels of PCBs in fish depend on factors such as trophic level, age and lipid content, as well as geographical distribution and the related exposure. Cod, which is a lean fish, will have higher levels of PCBs on a lipid-weight basis than fatty fishes like salmon. As an indication, a comparison of average PCB levels between cod and salmon on a wet weight basis shows lower levels in cod (3.96 ng/g ww) than in salmon (8-17.9 ng/ $\mathrm{g} \mathrm{ww}$ ) even though cod feeds at a higher trophic level than salmon (Johansen et al. 2004). PCB concentrations in low trophic level biota (i.e. amphipods) have been studied and reported earlier from the Barents Sea (Evenset et al. 2016; Hallanger et al. 2011a). $\Sigma \mathrm{PCB}_{7}$ concentrations varied between 0.4 and $3.2 \mathrm{ng} / \mathrm{g} \mathrm{lw}$ and are currently considered as background concentrations in Arctic zooplankton associated with the marginal ice zone. These studies also showed clear seasonal POP distribution differences that depend on environmental factors such as ice cover/melting as well as biological factors, e.g. feeding behaviour (Evenset et al. 2016; Hallanger et al. 2011b). A comparative study, in which enantiomerselective distribution patterns of chlorinated pesticides in low trophic level organisms were associated with ocean current profiles in coastal Svalbard, indicates the influence of oceanographic and climate variables on the pollutant pathways (Carlsson et al. 2014b; Hallanger et al. 2011a). It is, thus, scientifically confirmed that even low trophic level organisms bioaccumulate organochlorine contaminants and supports earlier observations (Borga et al. 2005a, b). The transfer of legacy POPs including PCBs from the lower trophic level organisms into the top predators of the Arctic (i.e. polar bear, glaucous gull, polar fox) along a typical marine and/or terrestrial food web is usually associated with the transfer of lipids (Fisk et al. 2001a; Kleivane et al. 2000). The studies conducted within ArcRisk showed the importance of understanding how secondary sources may impact the environmental fate of PCBs in the food web in the light of a changing climate. Increased melting and run-off from land will have impacts on the PCB input and transfer through the food web, beginning at lower trophic levels and continuing through the food web up to humans as end consumers.

\section{Contaminant profiles in a changing Arctic climate}

\section{Model-based forecasts of climate change impacts on PCB transport}

Climate change is expected to significantly influence the global transport pathways and fate of persistent organic pollutants (Armitage et al. 2011; Bustnes et al. 2010; Dudley et al. 2015; Friedman et al. 2014; Kallenborn et al. 2012; Kraemer et al. 2005; Macdonald et al. 2005; Octaviani et al. 2015; Wöhrnschimmel et al. 2013). For PCBs, the forecast increase in temperature will enhance degradation of PCBs and increase volatilisation and hence mobilisation from primary sources and environmental surface media, such as seawater, ice and soils (Ma et al. 2011). Changes in precipitation patterns are expected to affect the transfer processes between air and surface (Kallenborn et al. 2012). Melting land and sea ice will reduce the non-biological available storage capacity and influence air-surface transfer. Finally, changes in oceanic and atmospheric circulation will lead to altered transport pathways of PCBs. However, the quantitative impact of these processes is associated with considerable uncertainties. Therefore, a comprehensive modelling exercise was conducted in the frame of the ArcRisk project whereby a variety of model approaches was chosen to examine the influence of climate change scenarios on PCBs. The modelling expert group applied the following tools: Berkeley-Trent global contaminant fate model (BETR Research), Max-Planck Institute-MultiCompartmental Chemical Transport Model (MPI-MCTM), Danish Eulerian Hemispheric Model (DEHM) and coupled atmosphere-ocean general circulation model (ECHAM5MPIOM). ECHAM5-MPIOM also served as input to some of the other models. Each of these models has been applied individually to assess and evaluate potential impacts of climate change on PCBs and other POPs in the Arctic. Specific results from each model are summarised below. Further details regarding parameters and sources for the models can be found in their respective sections below.

\section{BETR Research}

BETR Research multimedia contaminant fate model was applied to model the impact of climate change on concentrations and distribution of PCBs in the Arctic. The emission history of PCB28 and -153, which has been published earlier (Breivik 
et al. 2007), was used for this purpose. Environmental parameters were mainly built on the BETR Global defaults (MacLeod et al. 2011) and the ECHAM5/MPI-OM model outputs for different IPCC AR4 scenarios (Winton 2006). The chemical properties of PCBs that were used are described in (Lamon et al. 2009). Long-term monthly averages from 1980 to 2000 were used for present-day scenarios, while time-evolving fields were used (Figs. 9, 10, 11, 12 and 13) for the climate change scenarios.

Climate change is projected to have a larger impact in the Arctic on PCB153 in seawater compared to atmospheric PCB153. While the relative increase of PCB153 is projected to be a factor 1.5 in Europe, it is up to a factor of 3-4 in the Arctic. These increases are a result of the higher relative atmospheric concentrations (a factor of 1.5 higher concentrations in the Arctic and a factor of 2 higher in European atmosphere) in combination with increased deposition into the Arctic Ocean, which is also facilitated by the decreasing sea ice cover. PCB28 also shows a relative increase in the model (a factor of about 2.5-3) in the Arctic Ocean, while it is projected to decrease in European seawater. However, that decrease might be within the parameter uncertainties (Figs. 10 and 12) and so is the climate change impact on PCB28 in the atmosphere as well (Figs. 9 and 10).

Even though the models projected significantly increased concentrations compared to the present-day scenario, the absolute concentrations by the end of the twenty-first century
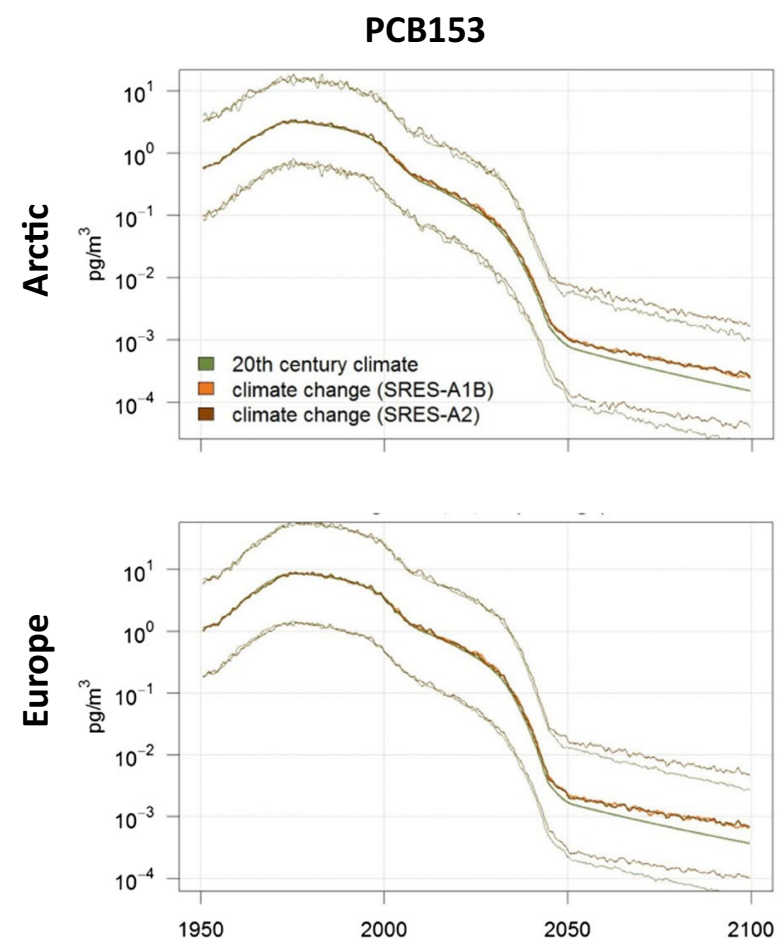

Fig. 9 Modelled PCB153 (left column) and PCB28 (right column) concentrations in the Arctic (upper row) and European (lower row) atmosphere, with and without climate change. The green middle line represents no climate change while the brown line indicates what were several orders of magnitude below the present concentrations in all scenarios. Temperature and its impact on volatilisation of PCBs from both primary and secondary sources are the main driver for the model results. The impact of climate change versus the reduction of primary emissions can be considered minor. Environmental degradation of PCB and especially the international legislations and bans on $\mathrm{PCB}$ production and usage are of major importance for decreased future $\mathrm{PCB}$ concentrations.

\section{MPI-MCTM}

Cycling of PCBs in a changing climate (A1B scenario of the IPCC AR4) was simulated using a multi-compartment chemistry-transport model which is based on a coupled atmosphere-ocean model (MPI-MCTM) (Guglielmo et al. 2009). According to the MPI-MCTM model, the effect of the changing climate on PCB is enhanced volatilisation from ice-free surface seawater but also enhanced storage of the compounds in the areas of the Arctic Ocean that are covered by ice, except in the Laptev Sea (Fig. 13). The contribution of precipitation to the substance cycling will also increase. The total environmental residence time (i.e. persistence; $\tau_{\mathrm{ov}}$ ) of PCB153 will be reduced by $40 \%$ in the 2090 s compared to the 1990s, mostly due to increased biodegradation in soil and water. However, due to shifting distribution towards soil and land ice, $\tau_{\mathrm{ov}}$ of the lighter PCB28 will increase in the Arctic. In
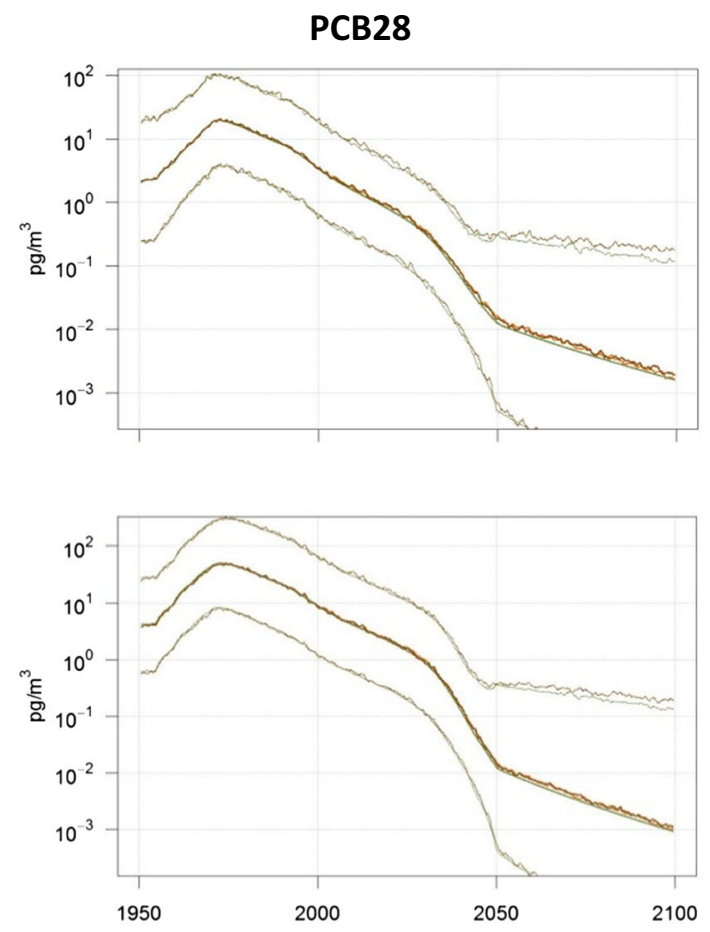

happens with $\mathrm{PCB}$ when climate change is taken into account. Uncertainties (95\% confidence interval) are indicated for PCB153 with the SRES-A2 scenario by the thinner lines. Please note the figure is reproduced from Wöhrnschimmel et al. (2013) 
PCB153
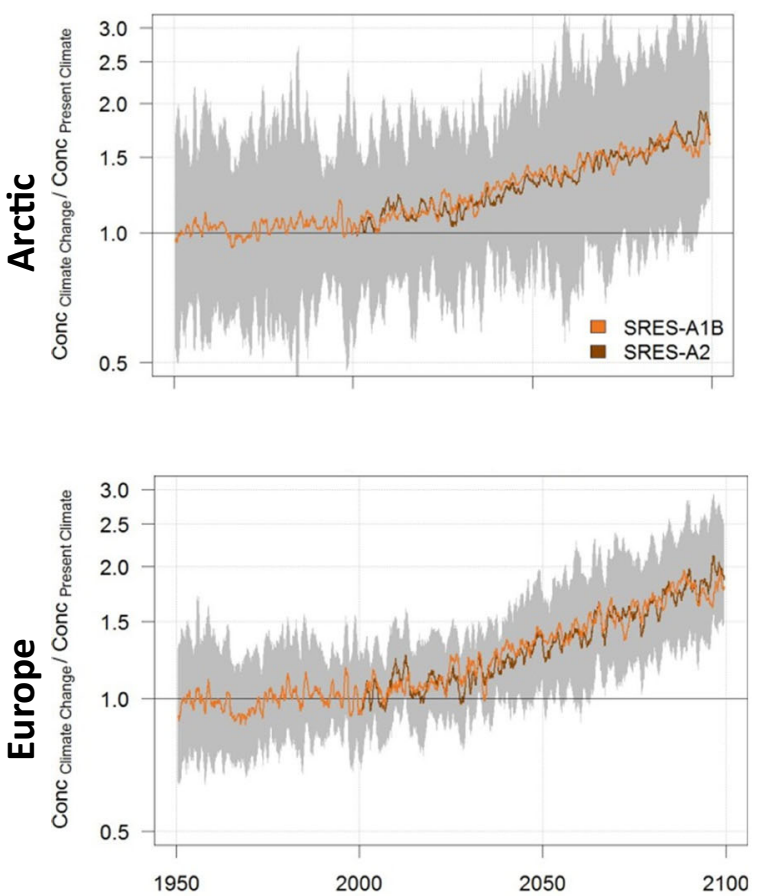

Fig. 10 Modelled relative change of PCB153 (left column) and PCB28 (right column) concentrations in the Arctic (upper row) and European (lower row) atmosphere. The green middle line represents no climate change while the brown line indicates what happens with PCB when
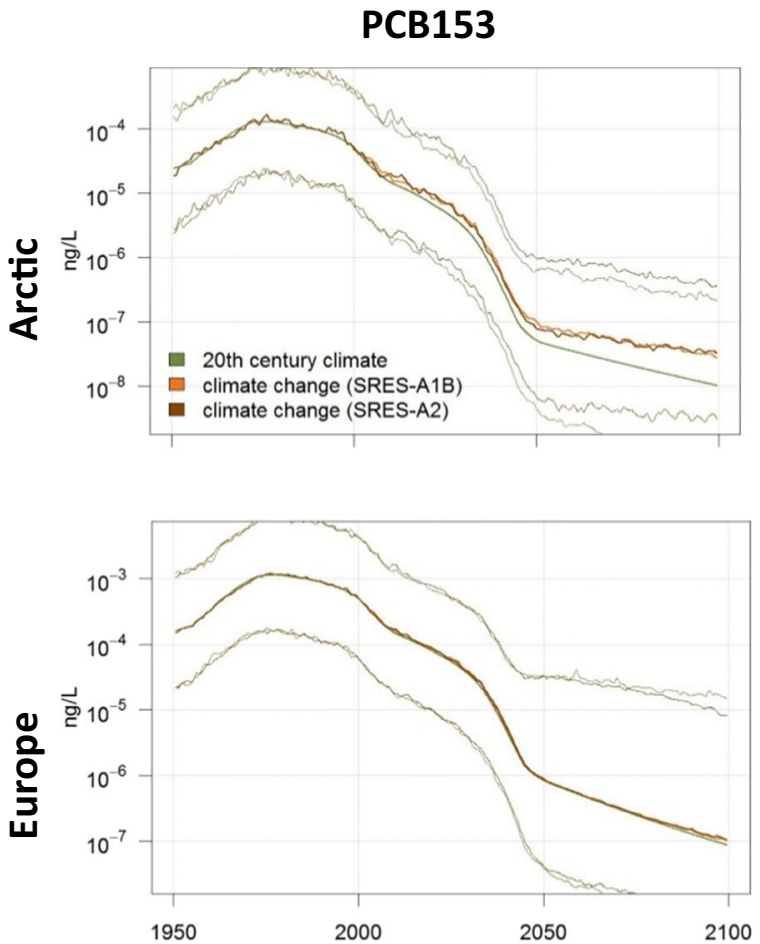

Fig. 11 Modelled PCB153 (left column) and PCB28 (right column) concentrations in Arctic (upper row) and European (lower row) seawater, with and without climate change. The green middle line represents no climate change while the brown lines indicate what
PCB28
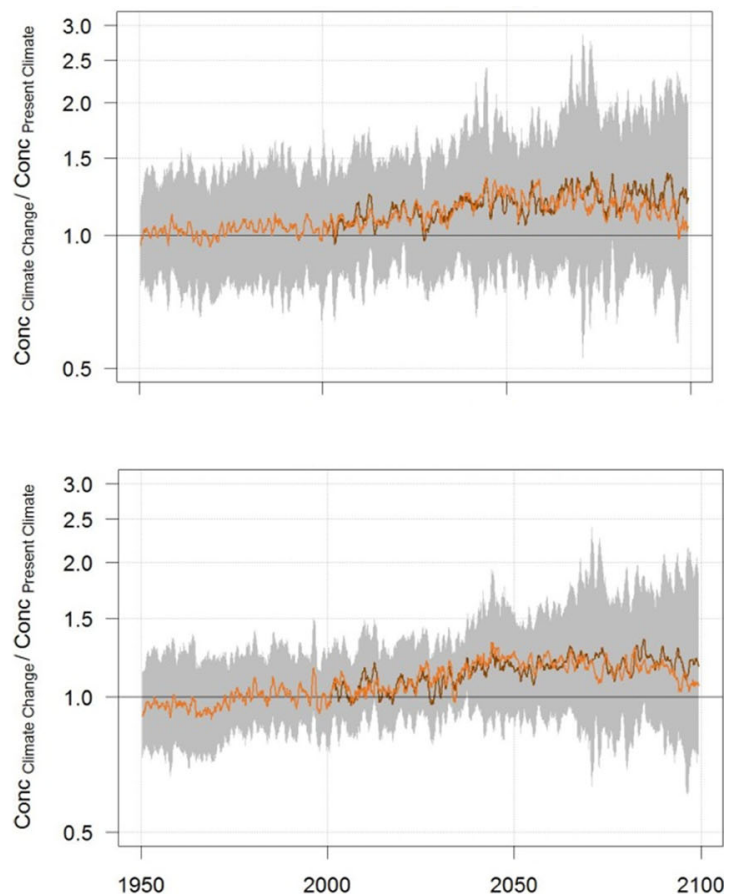

climate change is taken into account. Uncertainties (95\% confidence interval) are indicated for PCB153 with the SRES-A2 scenario by the shaded area. Please note the figure is reproduced from Wöhrnschimmel et al. (2013)
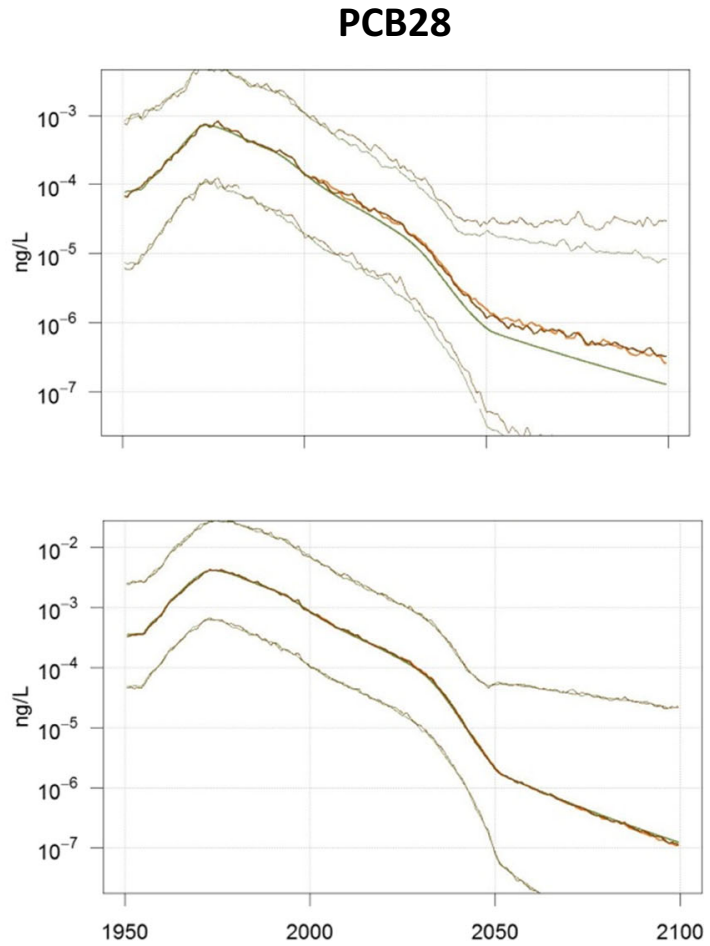

happens with PCB when climate change is taken into account. Uncertainties (95\% confidence interval) are indicated for PCB153 with the SRES-A2 scenario by the thinner lines. Please note the figure is reproduced from Wöhrnschimmel et al. (2013) 
PCB153
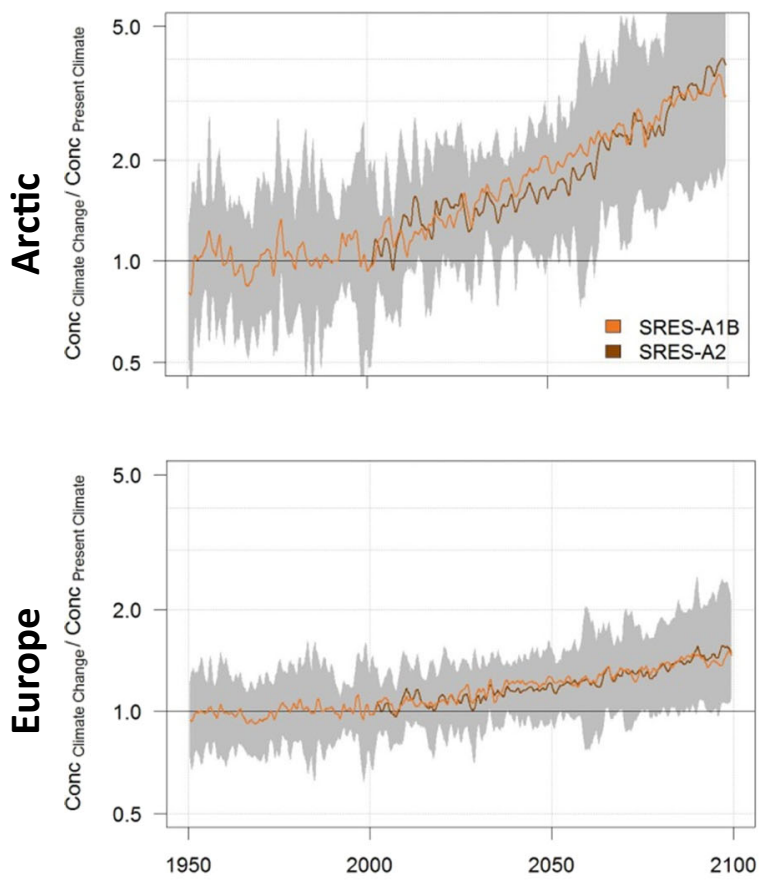

Fig. 12 Modelled relative increase of PCB153 (left column) and PCB28 (right column) concentrations in the Arctic (upper row) and European (lower row) sea water. The green middle line represents no climate change while the brown lines indicate what happens with PCB when

general, the climate change effect on PCB concentrations in soil, air and sea ice causes an increase, which, however, is by far smaller than the effect of decreasing primary emissions. Meridional long-range atmospheric transport of PCBs into the Arctic will continue to decline in this century, but the decline rate will level off (Octaviani et al. 2015).

\section{DEHM}

The DEHM was used to model the fate and transport of PCBs in the environment (Hansen et al. 2008). Two decades were compared in the forecast: 1990-1999 as a starting point and 2090-2099 as the 'end point' and climate data were taken from a model run of ECHAM5-MPI-OM simulating the SRES A1B scenario of IPCC AR4 (Semazzi 2003; Winton 2006). The initial conditions for the two time periods that were compared were the same and the PCB emissions were assumed to be identical to get a clear signal from the impact of climate change without changing emissions as an additional factor. Further details on model parameters and input are described in Hansen et al. (2008) and Hansen et al. (2015).

For PCBs with two to five chlorine atoms, including PCB28 and PCB101, modelled concentrations in the 2090 2099 time period in Arctic air were similar to or slightly lower in the atmosphere in comparison to the 1990-1999 time period and modelled concentrations in Arctic Ocean water and
PCB28
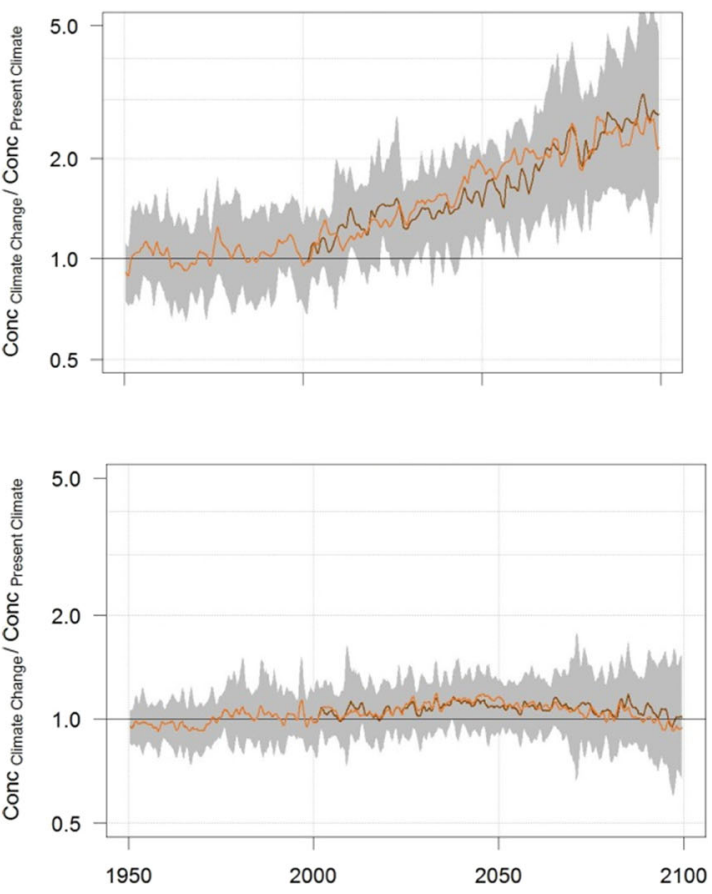

climate change is taken into account. Uncertainties (95\% confidence interval) are indicated for PCB153 with the SRES-A2 scenario by the shaded area. Please note the figure is reproduced from Wöhrnschimmel et al. (2013)

soils were lower by $20-40 \%$. For higher chlorinated PCBs such as PCB153, modelled concentrations in Arctic air were higher by about 5\% in the 2090-2099 time period (Fig. 14 middle), concentrations in Arctic Ocean water were lower by about $40 \%$ (Fig. 14 right) and concentrations in Arctic soils were close to identical (not shown). For the highestchlorinated PCB congeners that were considered (PCB180 and PCB194), modelled concentrations in Arctic air were 15\% higher in the 2090-2099 time period, modelled concentrations in Arctic Ocean water were 10\% lower and modelled concentrations in Arctic soils were slightly higher.

\section{ECHAM5-MPIOM}

Simulations were made using a multi-compartment chemistry-transport model which is consists of one general circulation model for the atmosphere coupled to an ocean general circulation model (ECHAM5-MPIOM). This model also includes an ocean-biogeochemistry sub-model (Guglielmo et al. 2012; Hofmann et al. 2012; Stemmler and Lammel 2012). The results indicate that for the A1B scenario of the IPCC AR4, more PCB153 will be associated with the particulate organic matter in water $c_{\mathrm{POC}}$, in particular the colloidal mass ('DOC') in the multi-phase seawater system. Therefore, bioavailability of this congener at the bottom of the marine food chain is expected to increase (Fig. 15). 


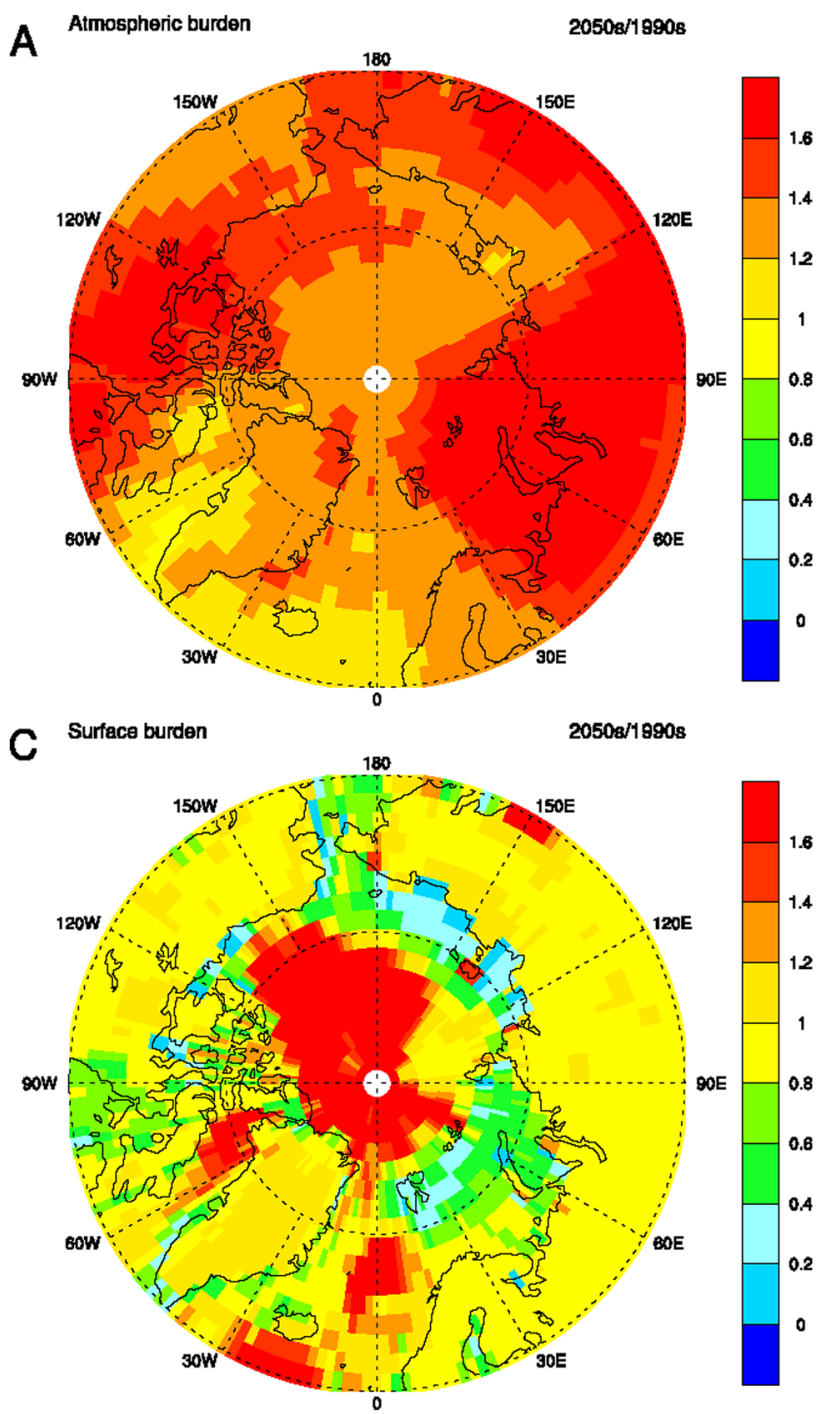

Fig. 13 Modelled mapped ratio of concentrations of PCB153 in the winter (DJF) atmosphere (a and $\mathbf{b}$, above) and surface compartments (c and $\mathbf{d}$, below), with and without climate change (A1B scenario of the
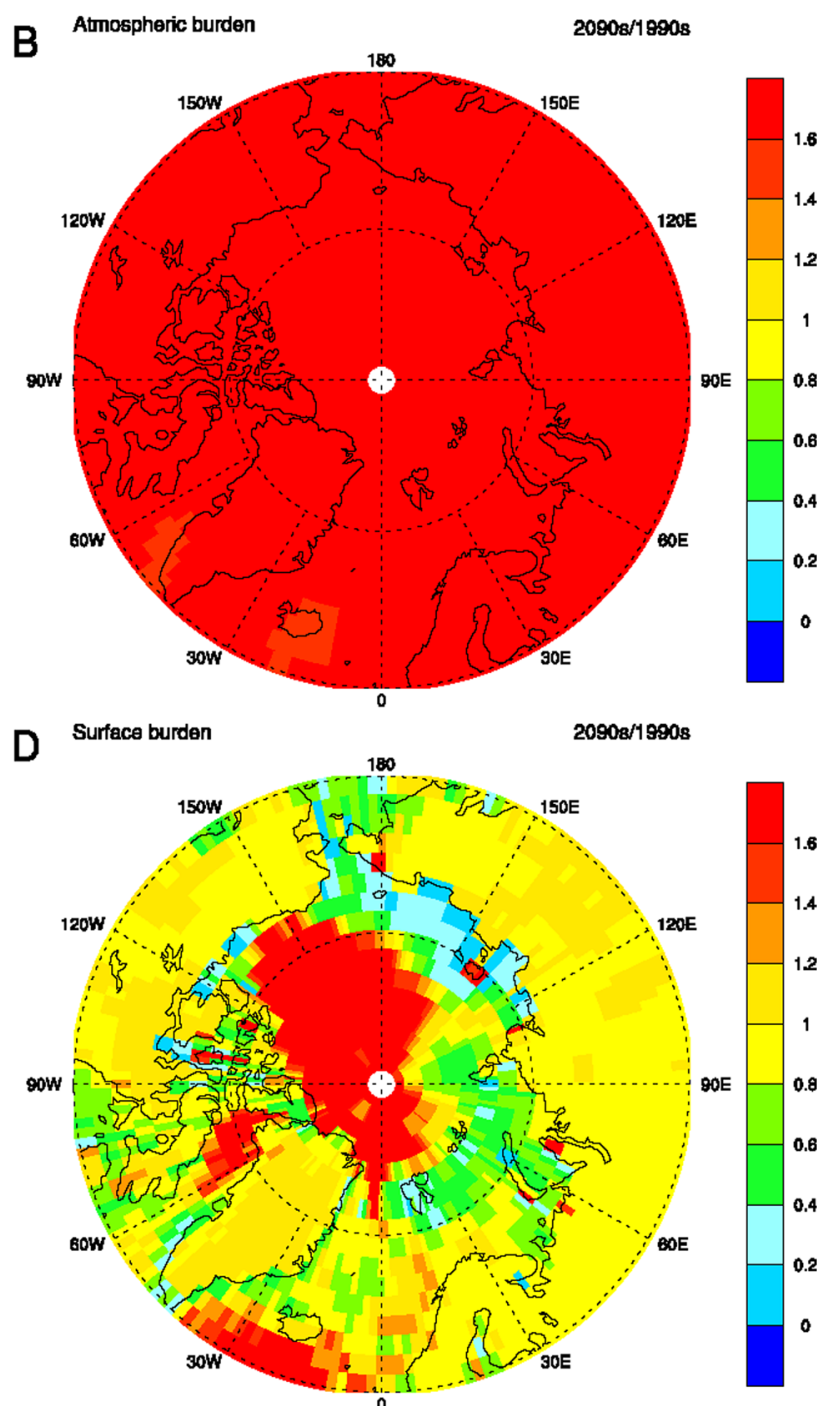

IPCC AR4) for the middle (a and c, 2050s/1990s) and end (b and d, 2090s/1990s) of the century. Values exceeding 1 indicate enhancement by climate change

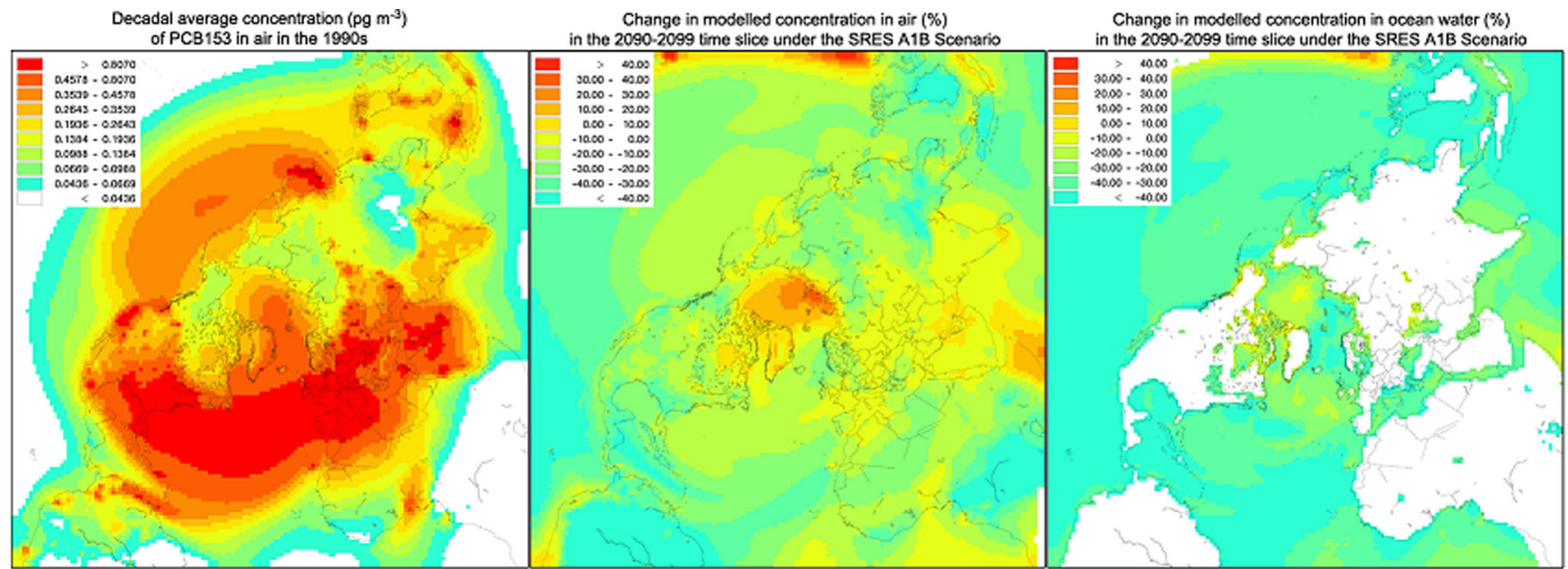

Fig. 14 Modelled decadal averaged atmospheric concentrations of PCB153 in the 1990s (left), the change in modelled concentrations in the 2090-2099 time slice under the SRES A1B climate scenario in air (middle) and in ocean water (right) 
Fig. 15 Present-day (annual mean of 2010) PCB153 mixing ratio in suspended organic phases, i.e. sum of dissolved and particulate organic carbon, and bulk phytoplankton and zooplankton (ng PCB/gC) in the Arctic Ocean

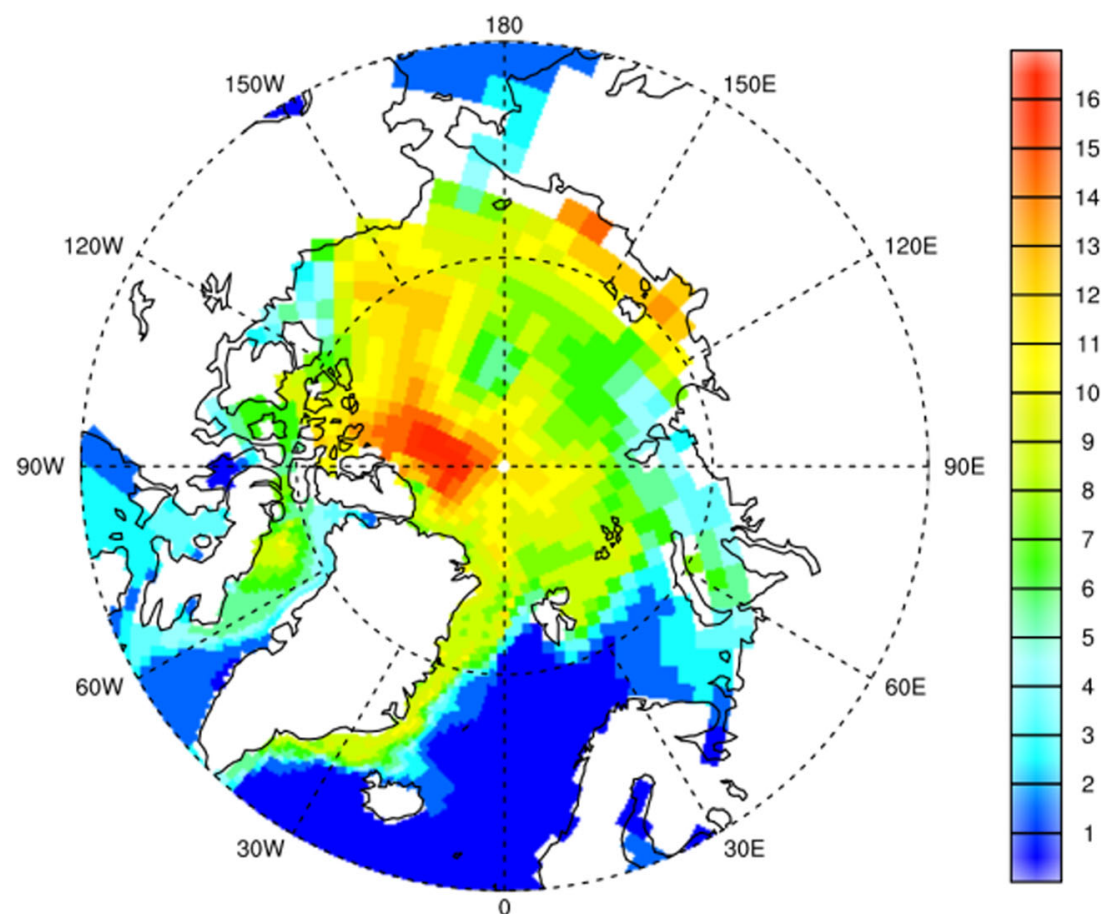

\section{Modelling output from the ArcRisk project}

All modelling tools used in the ArcRisk project agree upon most of the expected impacts of climate change on PCB concentrations in the Arctic. Their projected future (climate change scenario, neglecting emission reductions) concentrations are about a factor of 2 of relative increase compared to the baseline situation (today). The overall conclusion from the ArcRisk modelling studies is that the modelled concentrations of lowchlorinated PCBs in Arctic air are not as sensitive to climate change impact as the mid- and high-chlorinated PCBs are. Higher relative concentrations are expected for the mid-higher chlorinated PCBs under a climate change scenario (Lamon et al. 2009; MacLeod et al. 2011; Wöhrnschimmel et al. 2013).

Concentrations of PCBs in Arctic Ocean water are also higher under a climate change scenario according to BETR Research and MPI-MCTM results. In model experiments with DEHM that assumed the same emissions but different climate scenarios, modelled concentrations of PCBs in Arctic Ocean water were lower compared to BETR Research and MPI-MCTM projections under the climate change scenario.

The models BETR Research and MPI-MCTM suggest a similar role of global climate change on the atmospheric concentrations of highly chlorinated PCBs, e.g. PCB153, in both the Arctic and in the Baltic Sea region. The model results suggest increases in the atmospheric concentrations of these contaminants in the two regions with climate change compared to the present-day. The DEHM models forecast lower concentrations of high-chlorinated PCBs in seawater in the two regions, which is in agreement with the forecast of the multimedia chemical fate model POPCYCLING-Baltic that was adapted for the Baltic area (Kong et al. 2014). The pattern of Arctic Ocean water pollution is more heterogeneous in the MPI-MCTM simulation (Fig. 13) compared to DEHM.

\section{Biota exposure and PCB uptake in a warmer Arctic}

Processes governing bioaccumulation are temperature-dependent. In addition to the physical-chemical and biotransformation properties of PCB climate change will inevitably affect the velocity and environmental stability of environmental pollutants (Walters et al. 2016). Thus, changes in magnitude of relevance for bioavailability can be assumed for several climate change scenarios. In a changing Arctic environment, food web structures (including composition, availability of prey, etc.) are expected to change and these changes within environmental processes will impact the environmental fate of pollutants in the Arctic ecosystem (Boonstra 2004; Fisk et al. 2001b; Hallanger et al. 2011a, b; Kallenborn et al. 2012; Riget et al. 2013).

\section{Bioavailability}

Bioavailability can be defined in two distinct ways according to an earlier comprehensive report (Gobas and Morrison 2000): 
1. The fraction of the total concentrations, in a specific medium or matrix (e.g. water and sediment) that can be absorbed by the organisms via a specific route of uptake

2. The rate or the extent to which a chemical is absorbed and accumulated by the organism

The ArcRisk work was mainly related to point (1). Bioavailability according to point 1 is largely controlled by the distribution of POPs between the phases of environmental matrices. For example, a POP's bioavailability in water would be controlled by the distribution between the dissolved, particulate and dissolved organic matter phases. This distribution would be influenced by the physical-chemical properties (e.g. the octanol-water partition coefficient, $\mathrm{K}_{\mathrm{OW}}$ ) of the PCBs, the particulate concentration in the water column, the properties of the particulate matter phases (e.g. organic matter content) and temperature. Temperature changes resulting from global climate change would therefore have a direct influence on partitioning of POPs in natural waters. For example, in the Baltic Sea, the equilibrium partitioning of hydrophobic organic contaminants between the particulate and dissolved phases in water decreased by a factor of five with a temperature increase of $20^{\circ} \mathrm{C}$ (Smith and McLachlan 2006).

Borgå et al. (2010) used an aquatic bioaccumulation model to simulate the effect of global climate change on POP bioaccumulation in an Arctic marine pelagic food web. In this modelling approach, it was assumed that climate change would result in increasing primary productivity in the Arctic Ocean, resulting in increasing concentrations of particulate organic carbon (POC) in the water column. Borgå et al. (2010) also considered the effects of temperature on changing respiration, consumption and growth rates of species in the food web studied. Three chemicals were considered: $\gamma$ $\mathrm{HCH}, \mathrm{PCB} 52$ and PCB153. In each case, a decrease in bioaccumulation was predicted because of global climate change. In the top-predator cod (G. morhua), these changes ranged from being negligible for $\gamma-\mathrm{HCH}$ to a $50 \%$ decrease for PCB153. These decreases were primarily controlled by reduced bioavailability resulting from dilution of the chemical in the larger mass of POC due to the assumed increase in primary productivity. Therefore, the effect of increased temperature on partitioning discussed above was offset by the increase in POC. It should be noted that simulating how global climate change will affect future primary productivity in the oceans is highly uncertain (Cousins et al. 2011a, b). For example, contrary to the assumption of Borgå et al. (2010), Boyce et al. (2010) observed a decrease in primary productivity in the Arctic Ocean and associated this decrease to limited nutrient supply caused by temperature-driven stratification of the surface oceans.

We conclude from the above discussion that the major impact of climate change on bioavailability is likely due to changes in distribution between exposure media due to increasing temperature or changes in the primary productivity as opposed to the direct bioenergetic impacts of temperature on PCB uptake through changes in food consumption or metabolic rate. Large uncertainties remain, however, concerning how primary productivity in the world's oceans will be affected by global climate change. This information was developed in ArcRisk and incorporated into models and experiments during the project.

\section{Food web transfer variations in a changing Arctic climate}

Climate change can impact environmental processes and the transfer pathways of POPs within the food web such as bioavailability (as discussed above), metabolism and trophic structure. Cousins et al. (2011a, b) and Gouin et al. (2013) have reviewed the impact of climate change on bioaccumulation of POPs in food webs, and their main conclusions were that 'indirect' effects (e.g. changes in human diets, species distribution and primary productivity) are likely to be of higher importance for humans and the environment compared to 'direct' effects (bioenergetic processes, such as consumption rate, metabolism and growth). However, indirect effects are much more difficult to include in models as well as in empirical studies. Hence, we need better and more thorough understanding of trophic interactions and changes within the food web to fully understand the impact of climate change on bioaccumulation of PCBs in the future.

\section{Contemporary and future human exposure scenarios}

PCBs and other POPs may enter humans via air, food or through contact with the skin (Cao et al. 2014; Linares et al. 2010; Lorber 2008; Turyk et al. 2009). Among these entry routes, the diet is the major source of PCBs, especially fatty fish, meat and dairy products. PCBs have been detected in a suite of body tissues and fluids such as maternal and children's blood and/or serum, cord blood, foetal adipose tissue, placenta, infant blood, blood from males and breast milk in Arctic peoples (AMAP 2015; Nøst et al. 2013; Bonefeld-Jørgensen 2004; Donaldson et al. 2010; Dudarev et al. 2004; Hansen 2000; Klopov et al. 1998; Nøst et al. 2013). In the blood of breast-fed infants, the concentration may be many times higher than in maternal blood (Boucher et al. 2010). PCBs have a long half-life in the body and by fitting a populationlevel pharmacokinetic model to biomonitoring data for human blood, half-life estimates of 15.5 years for PCB170, 14.4 years for PCB153 and 11.5 years for PCB180 were estimated (Ritter et al. 2011). PCBs that are not bio-transformed are only slowly excreted, mainly through the faeces, urine and breast milk. Throughout the past few decades, a variety of more or less subtle effect endpoints such as activation of the aryl- 
hydrocarbon receptor (AhR) and the pregnane $\mathrm{X}$ receptor (PXR), foetus development and mental development among children have been identified in the literature, especially based on Arctic studies (Abass et al. 2013; Bonefeld-Jørgensen 2004; Deutch et al. 2007; Donaldson et al. 2010; Hansen 1998, 2000; Hansen et al. 2002; Hansen et al. 2010; Klopov et al. 1998; Letcher et al. 2010; Odland and Nieboer 2012).

\section{Toxicokinetic modelling and future risk predications}

Several earlier trend studies report PCB levels in Arctic indigenous populations (Donaldson et al. 2013; Dudarev 2012; Gibson et al. 2016; Kruger et al. 2012; Ryan and Rawn 2014; Schaebel et al. 2017; Singh and Chan 2017; Valera et al. 2013a, b; Veyhe et al. 2015).

PCB153 is among the most prevalent PCB congener found in human populations and as such has been one of the indicator PCBs for monitoring in biota (Fisk et al. 2005; Gewurtz et al. 2006; Gomez-Ramirez et al. 2014; Kalinovich et al. 2008; Letcher et al. 2010; Wolkers et al. 2006; Xu et al. 2013). The trend of geometric mean concentration (declining for all three locations) of PCB153 in plasma lipid from pregnant women during the years 1992-2007 in Inuit women from Disko Bay and Nuuk (Greenland) and Nunavik (Quebec, Canada) is shown in Fig. 16. The decreased concentrations of PCB153 in pregnant women from the Disko Bay area may be due to a decrease in the consumption of traditional food originating from animals at high trophic levels. There has clearly been a trend for decreased exposure to PCB153 in Arctic. The lower concentrations in Nuuk women compared to Disko Bay are most likely due to lower consumption of traditional diet that is rich in marine mammals in Nuuk (largest town in Greenland) compared to the more rural Disko Bay. The geometric mean concentration of PCB153 (Fig. 16) measured in plasma lipid has decreased from 111 to $172 \mu \mathrm{g} / \mathrm{kg}$ plasma lipids during the $1990 \mathrm{~s}$ to $40-79 \mu \mathrm{g} / \mathrm{kg}$ plasma lipids during early $2000 \mathrm{~s}$ at all three locations (Abass et al. 2013). The analyses of trends and data continue after the ArcRisk work as well and can be found in the recent AMAP assessment (AMAP 2015, p. 2015).

PCB153-associated human health effects and risks were assessed using data obtained from the AMAP biomonitoring programme presented above and a one-compartment population-based pharmacokinetic model. The aim within ArcRisk was to extrapolate body burden and exposure to the whole lifespan of the population. The results of the modelled body burden are presented in Fig. 17.

A hazard quotient (HQ) is the average daily dose (ADD) divided by a reference dose (RfD) and gives an estimate of non-cancer related effects. Abass et al. (2013) used HQ to estimate the exposure to PCB153 (Fig. 18) during recent decades for Arctic human populations. The 90th population percentile during the years 1955-1987 and the 50th population percentile during 1956-1984 had HQ > 1, which means that the exposure may cause a potential adverse, non-cancer health
Fig. 16 PCB153 concentration trends (geometric mean and range) in plasma lipid $(\mu \mathrm{g} / \mathrm{kg})$ among pregnant women from Disko Bay (Greenland), Nuuk (Greenland) and Nunavik (Quebec, Canada) in the period 1992-2007. Reprinted (Abass et al. 2013) with permission of Elsevier

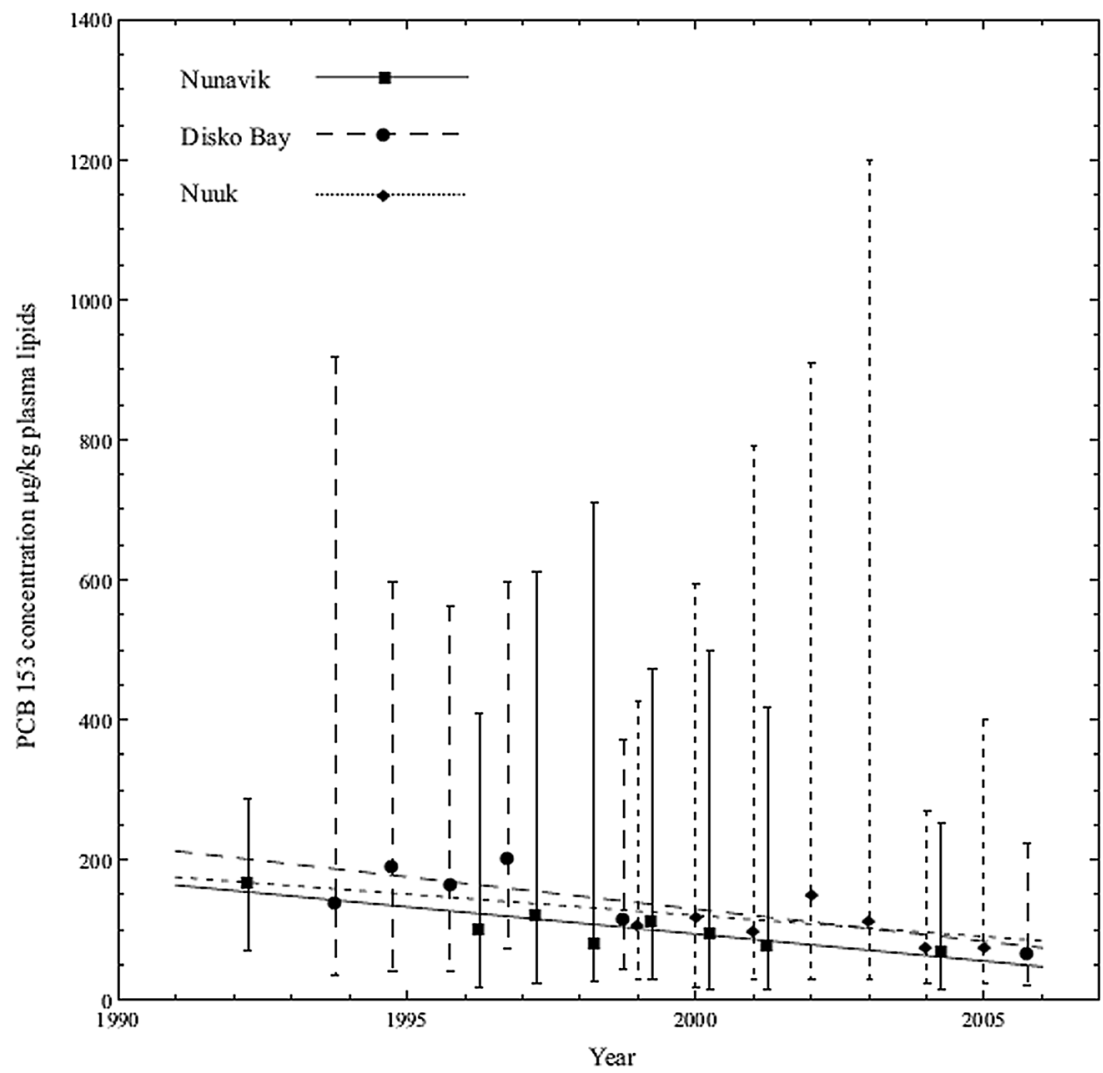




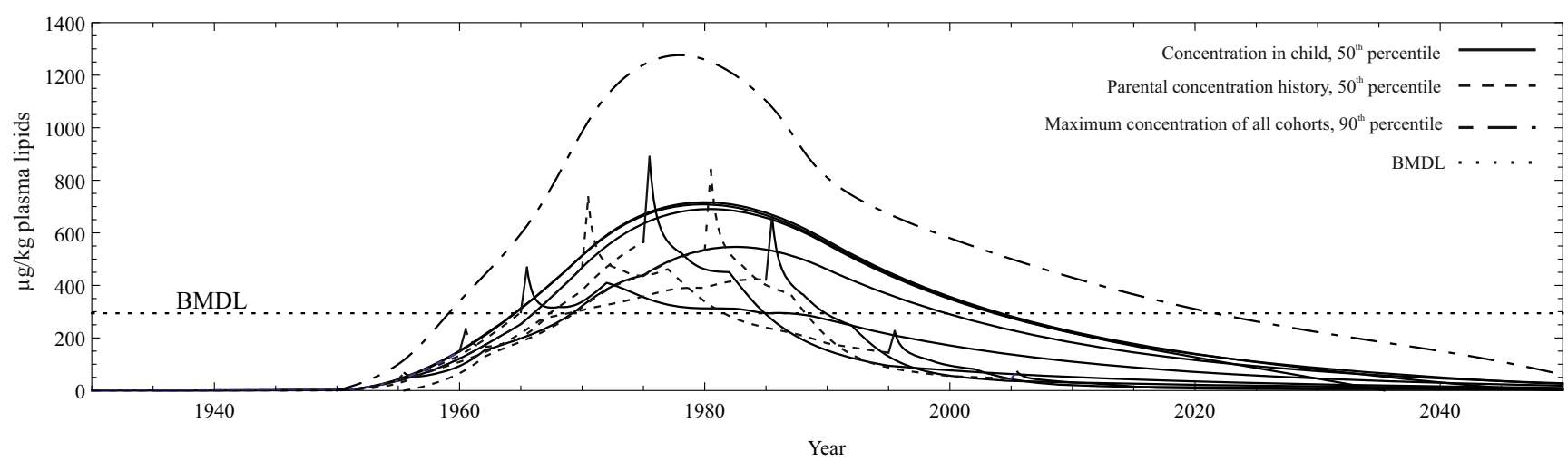

Fig. 17 Extrapolated concentrations of PCB153 ( $\mu \mathrm{g} / \mathrm{kg}$ plasma lipids) in pregnant Inuit women from Nunavik, Disko Bay and Nuuk for different birth cohorts of 1940, 1950, 1960, 1970, 1980 and 1990. The estimated concentrations of PCB153 in plasma lipids for the 50th and 90th population percentiles of birth cohorts are given and shown. Both estimates, the dotted and solid curve for 50th population percentile

effect. Cancer risk related to PCB153 was also estimated within the same study and the range for the 90th percentile was from $4.6 \times 10^{-5}$ to $1.8 \times 10^{-6}$ between 1930 and 2049 (Fig. 19). Further details on methods and results are described in Abass et al. (2013). This kind of toxicokinetic modelling in combination with the United States Environmental Protection Agency Integrated Risk Information System (US-EPA-IRIS) risk assessment framework proved to be very useful for prediction and assessments of human health risks related to POPs.

\section{PCBs in Arctic and European populations}

As a part of the ArcRisk project, a survey including both Arctic (Norway) and European cohorts (Spain) was conducted and the results for PCB153 in blood serum are shown in Fig. 20. The highest exposure was found among participants while dashed envelope estimates maximum concentrations of all birth cohorts for 90th of population percentile. They are based on the curves of reference daily intake presented in Figs. 18 and 19. The health risk of PCB153 is estimated by using a benchmark dose level (BMDL) of 300 as a toxicological cutoff point. Reprinted (Abass et al. 2013) with permission of Elsevier

in the Norwegian Fish and Game (NFG) study, while participants in the Spanish INfancia y Medio Ambiente: Environment and Childhood (INMA) and the Northern Norway Mother-and-Child Contaminant Cohort Study (Norwegian MISA) studies had the lowest exposure. However, the participants in the NFG study were older (median, 55 years; range, 21-80 years) than the participants in the other studies and, hence, higher concentrations could be expected. Furthermore, participants in the NFG high consumer group were invited due to high consumption of food that generally contains higher levels of POPs compared to other food items. Human PCB exposure is decreasing in several regions and hence the sampling year should be noticed (Donaldson et al. 2010). The NFG study samples were from 2003, while the sampling period and ages are more comparable between birth cohort mothers from Spain (INMA, sampling years 20042008, except Menorca which was sampled 1997-1999) and

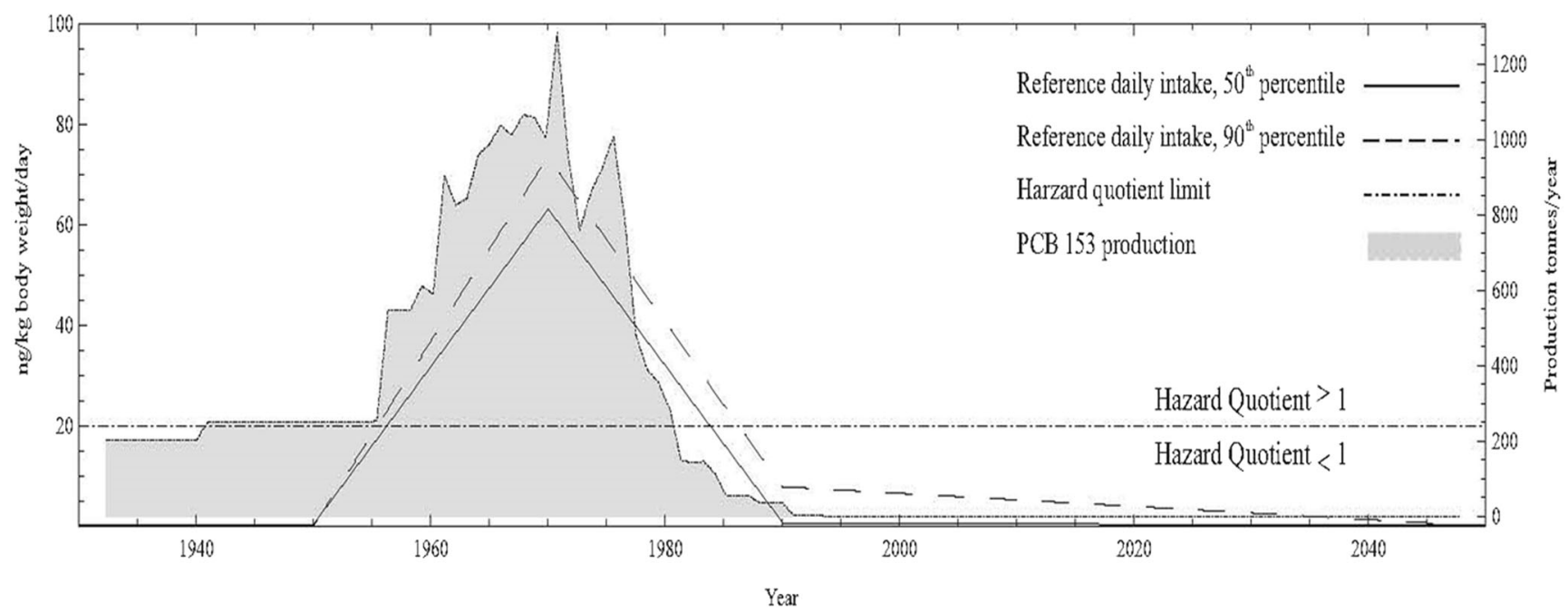

Fig. 18 Modelled reference daily intake (ng/kg-bw/day) of PCB153 for an adult (50th and 90th) and production trend of PCB153. Reprinted (Abass et al. 2013) with permission of Elsevier 


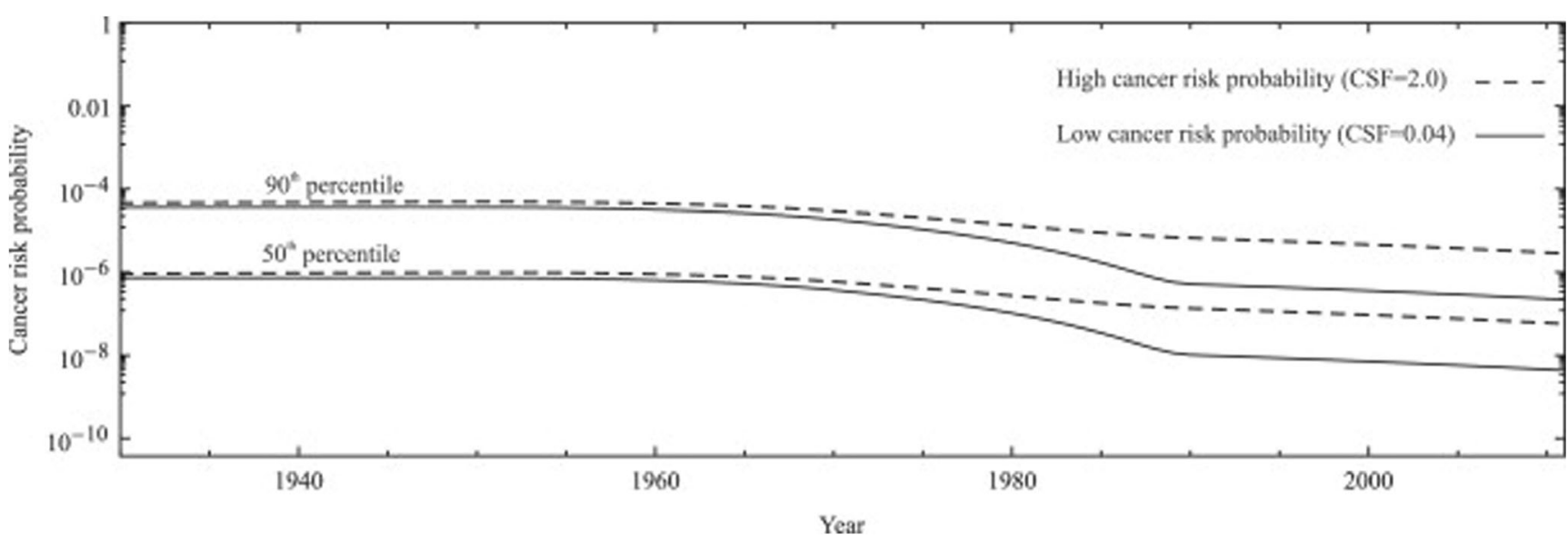

Fig. 19 Cancer risk probability estimates for the high (cancer slope factor, $\mathrm{CSF}=2.0$ ) and low $(\mathrm{CSF}=0.04)$ slope factors for the 90th and the 50th percentiles of the birth cohorts. The year-axis indicates the time of birth of the cohort. Reprinted (Abass et al. 2013) with permission of Elsevier

Arctic Norway (MISA, sampling years 2007-2009). The mean and upper range of exposure (both in maternal and cord blood) was higher among the INMA participants compared to the MISA cohorts. Thus, this first comparison indicates that women of fertile age living in Spain have higher PCB exposure than women in the northern part of Norway (BrorströmLundén et al. 2013; Fernandez et al. 2007; Guxens et al. 2012; Llop et al. 2017; Morales et al. 2013).

A study on POP distribution in the very same Norwegian men sampled from 1979 to 2007 (Nøst et al. 2013) showed declining concentrations for all POPs (Fig. 21) except for chlordanes (e.g. trans-nonachlor). Decreasing trends were observed from 1979 and onwards in concentrations of most penta- and hexa-chlorinated PCBs. On the contrary, heptachlorinated PCBs increased from 1979 to 1986, before they began to decline (Fig. 21). Nøst et al. (2013) showed that the POP concentrations decreased during 1979-2007 in men from Northern Norway and that the average $\Sigma$ POP concentrations in 2007 were one third of the concentrations measured in 1979. The years 1979 and 1986 had the peak PCB153 concentrations, which confirm that this period was the one with the highest human exposure. The decreasing trends in serum concentrations likely reflect declining environmental concentrations due to reduced emissions during the same time period.

\section{Scenarios of future of human exposure and potential health effects of PCBs in the Arctic}

Risk assessment studies of pollution-related health effects in Arctic populations are usually conducted using long-term retrospective epidemiological studies. Even though there is a lot of existing information on the topic, few studies report relationships between POP levels and human health or healthrelated endpoints. Hence, ArcRisk therefore conducted a comprehensive meta-data analysis of results from the Arctic population studies on health effects. Three systematic review articles (Candolin et al. 2014; Nieminen et al. 2013a; Nieminen et al. 2013b) on the association between PCB exposure levels

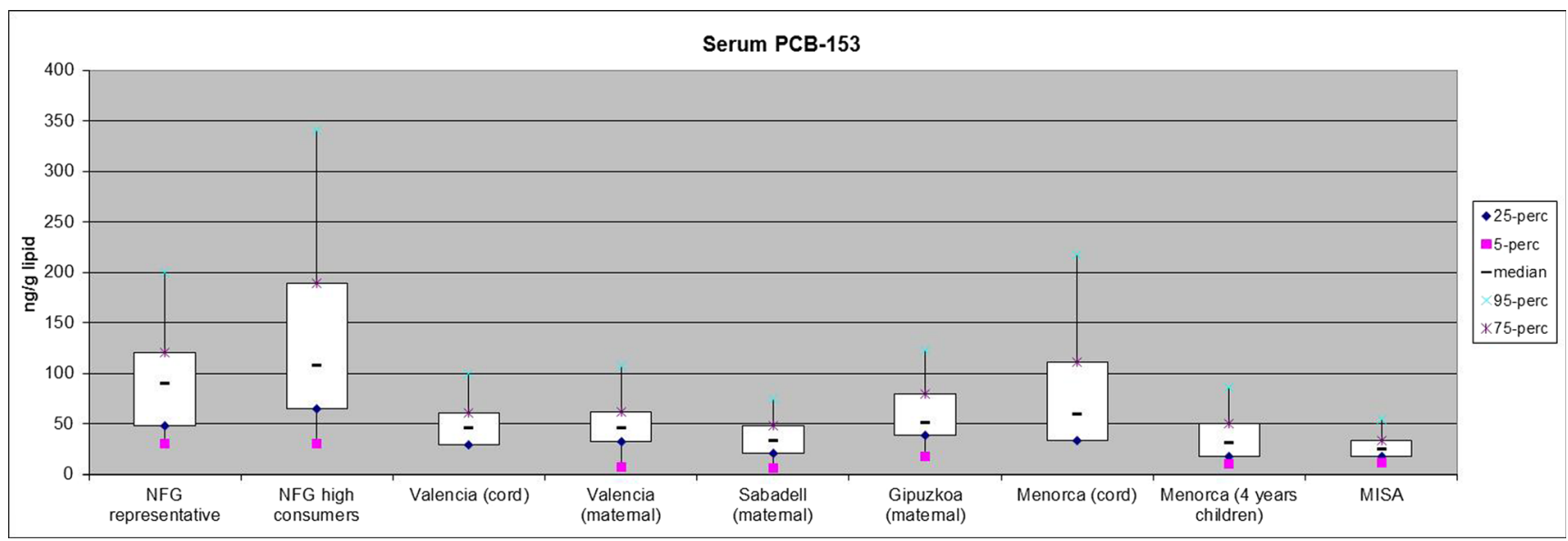

Fig. 20 Overview of serum PCB 153 concentration in ArcRisk study groups. NFG = Norwegian Fish and Game study, MISA = Northern Norway Mother-and-Child Contaminant Cohort Study 


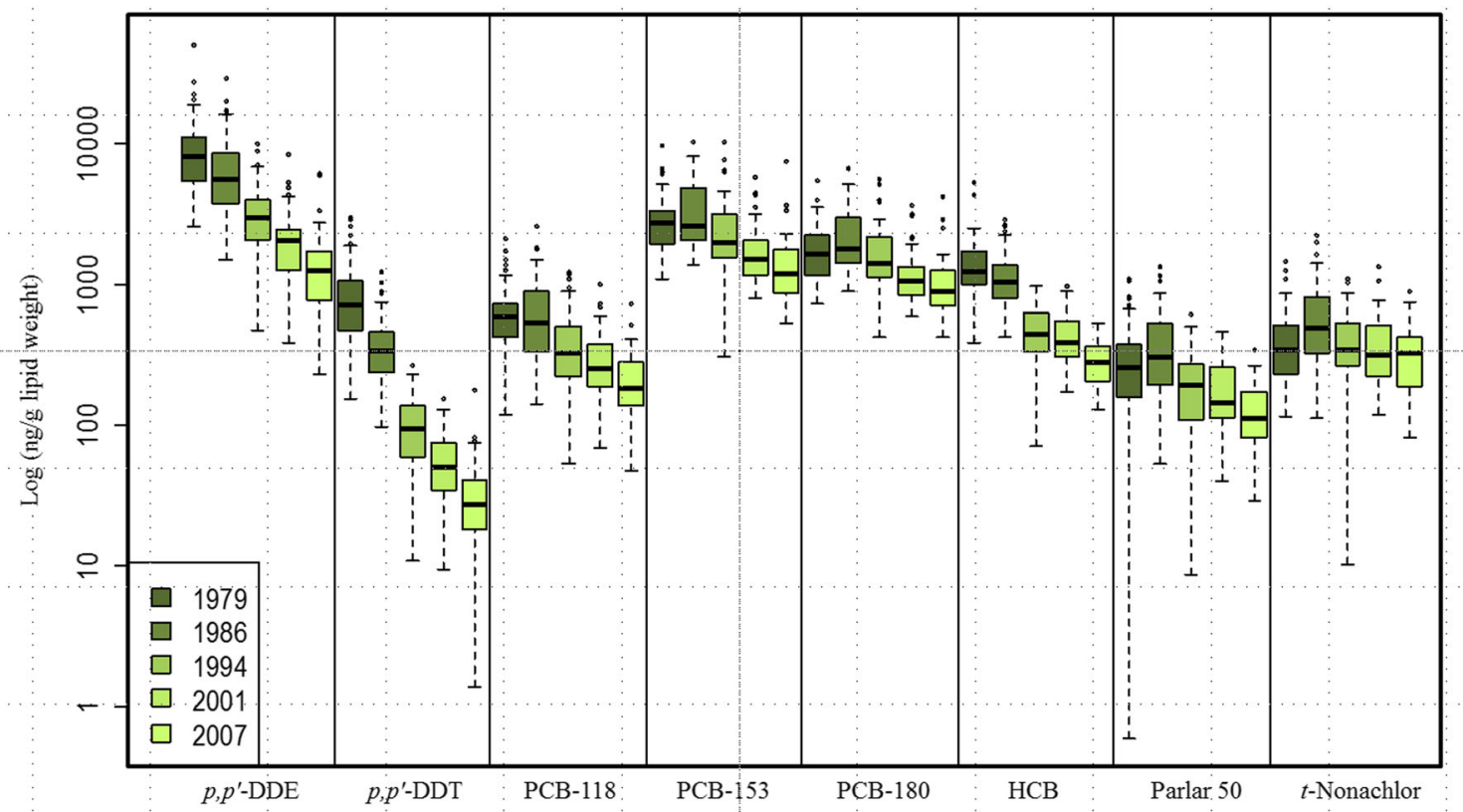

Fig. 21 Concentrations (ng/g lipid, $y$-axis: $\log$ scale) of selected POPs analysed in repeated serum samples of men $(N=51,51,45,48$ and 52 in 1979, 1986, 1994, 2001 and 2007, respectively) from Northern Norway. Parlar 50 represents toxaphenes and $t$-nonachlor the chlordanes. Boxes extend from the 25th to the 75th percentile, horizontal bars represent the

and secondary sex ratios identified the following limitations with respect to meta-analysis on health effects of PCBs:

1. The number of relevant articles with epidemiological data is very limited.

2. The findings of epidemiological studies are analysed and reported in ways that are often not comparable.

3. Results across repeated studies of the same phenomena are rarely identical due to reasons that include differences in analytical methods and genetic differences between the populations studied.

4. Different statistical methods are used in different studies and publications even though their main aims are identical, e.g. investigations of the relationship between PCB exposure levels and health outcomes.

5. The quality of method descriptions also varies: detailed descriptive statistics of the variables included and standard error for regression coefficients and/or the mean differences were not always reported.

\section{Summary and conclusions}

The ArcRisk research team conducted research on long-range transport, occurrence and fate, exposure and health impacts of selected contaminants in Europe and the Arctic during a 4year period (2009-2013). The ArcRisk research, combined median and whiskers extend 1.5 times the length of the interquartile range (IQR) above and below the 75th and 25th percentiles, respectively; any outliers are represented as points. ${ }^{*} p<0.05$ and $* * p<0.001$ for comparisons between pairs of consecutive sampling years. Please note the figure is reproduced from Nøst et al. (2013)

with results from complementary studies, contributed significantly to the current scientific understanding on the influence of climate change on $\mathrm{PCB} /$ pollutant distribution, cycling and effects in the Arctic. The combined results from models, measurements and studies on health effects have been compiled to provide an overall picture of PCBs and to describe the links between emissions and health effects in the Arctic. This review presents a comprehensive overview on PCBs that shows our current understanding of the complex relationships between sources, transport, bioaccumulation, exposure and health impacts of PCBs in relation to climate change, especially for Arctic environment and human populations.

The most relevant climate parameters that impact transport pathways of PCBs to the Arctic and environmental processes in the Arctic environment are changes in temperature, precipitation, sea and land ice cover and the global circulation of the atmosphere and the oceans.

\section{Emissions}

Emissions of PCBs still occur from, e.g. buildings and waste dumps (e.g. primary sources), although at decreasing rates. Secondary emissions of PCBs accumulated in environmental reservoirs (sediment, water, soil, snow and ice) are becoming more important than primary sources. Climate change will most likely increase primary and secondary emissions relative to levels that would be expected under current conditions but 
not to an extent that the overall decreasing trend of PCBs in the remote environment will be confounded.

\section{Important pathways to the Arctic}

Atmospheric long-range transport is a major route for the global distribution of PCBs to the Polar Regions and deposition from the atmosphere is an important pathway of PCBs to both terrestrial and marine environments in the Arctic.

In addition to long-range transport via the atmosphere, transport via oceanic currents is also important for the occurrence of PCBs in the Arctic. Climate change is likely to affect all these pathways and their subsequent environmental fate.

The legislation covering PCBs that began in several countries during the 1970s has had the desired effect. However, with the large quantities of PCBs used and their persistence, we still see ongoing emissions of PCBs, and hence they are present in biotic and abiotic matrices all over the world. Lessons learnt from studies of trends of PCBs confirm that legislation in combination with long-term monitoring remains a very important tool for decreasing the environmental and human health-related risks associated with persistent, toxic and bioaccumulating compounds.

\section{Key processes}

Precipitation was identified as an important factor for PCBs present in surface compartments such as the seasonal and perennial snow pack (the latter associated with ice caps for example). Climate-related effects such as changes in precipitation patterns and erratic and longer snow-melt periods will influence the accumulation and release of PCBs from cryospheric compartments like snow, firn and ice.

PCBs can accumulate in young/single-season sea ice thus providing a chemical stock for surface marine waters although it is unclear how the changing nature of sea ice-its composition (first-year ice vs multi-year ice) and areal cover-will affect the pathways and mobility of PCBs in surface marine waters. During pronounced seasonal thaw, accumulated contaminants like PCBs will be released to the water thus providing a focused exposure mechanism for ice-associated organisms at the base of the marine food web.

In total, PCB releases from sea ice and snow do not provide large inputs to the Arctic oceans in comparison to those forecast for the major pan-Arctic rivers that drain into coastal Arctic seas.

\section{Impact of climate changes on PCBs in the Arctic}

The outcome from the models used in ArcRisk indicated that $\mathrm{PCB}$ concentrations will show a relative increase in the Arctic Ocean and atmosphere, mostly due to the climate change impact on temperature, which will affect the volatilisation of
PCBs from both primary and secondary emission sources. Atmospheric PCB concentrations have been decreasing in the Arctic during the last few decades. Although some of the modelled concentrations of PCBs were higher under the climate change scenarios, the absolute concentrations are forecast to be several orders of magnitude below present levels in all scenarios by the end of the twenty-first century. This is directly linked to the long-term reductions in primary emissions.

It is important to remember that the models do not include all factors that may influence future PCB emissions/transport. Increased transport (shipping, air traffic, etc.) and tourism in the Arctic and changes in diet among indigenous peoples are all examples of factors that can be of high importance for assessing the future or changing impact of PCBs on human health and the Arctic environment, but these factors are extremely difficult to incorporate into a model. Climate change modelling is complex and indirect effects such as changes in vegetation cover, animal distribution and land usage are not included in the total assessment of PCB behaviour. Nevertheless, ArcRisk has helped to fill knowledge gaps as well as identify research areas where knowledge on the impact of environmental pollutants on human and ecosystem health in the Arctic in a changing climate is needed.

\section{Bioavailability, food web transfer and concentrations in biota}

One of the most important factors that climate change affects is the temperature, which is a driver for several other environmental processes, including partitioning of PCBs between air, water, soil and biota. Hence, climate change may cause changes in PCB distribution and thereby exposure pathways for biota, e.g. impacts on primary production, which may change the amounts of particulate or dissolved organic material (POM/DOM).

\section{Human health}

PCB concentrations will decrease over time in humans, mainly owing to implementation of international legislation. There are still knowledge gaps on the risk assessment of PCBs on human health due to the relatively small number of studies and difficulties in comparing among studies, although metaanalysis studies can provide good overviews and data for these risk assessments. For indigenous peoples, changes in diet associated with increased consumption of imported processed foods as well as switches to different species depending on seasonal abundance and climate-induced changes in species composition are likely to have the most marked effect on $\mathrm{PCB}$ exposure in the near future. 
Acknowledgements This review would not have been possible without the support and help of many contributors and organisations. We are especially grateful for the contribution from Therese H. Nøst, Deguo Kong, Örjan Gustafsson and Hanna Andersson during the ArcRisk project.

Arctic Health Risks: Impacts on health in the Arctic and Europe owing to climate-induced changes in contaminant cycling (ArcRisk) was funded by the Seventh European Research Framework Programme (FP-7) (Grant agreement 226534). The Arctic Monitoring and Assessment Programme (AMAP) provided the professional network and the Coordinator for the ArcRisk project.

The Nordic Council of Ministers (NCM) as well as the Research Council of Norway ( $\mathrm{RCN}$ ) provided funding for several supporting studies reported here. The significant in-kind contributions of all institutions (see author list) involved in ArcRisk and other projects reported here are greatly appreciated.

\section{Compliance with ethical standards}

Conflict of interest The authors declare that they have no conflict of interest.

Open Access This article is distributed under the terms of the Creative Commons Attribution 4.0 International License (http:// creativecommons.org/licenses/by/4.0/), which permits unrestricted use, distribution, and reproduction in any medium, provided you give appropriate credit to the original author(s) and the source, provide a link to the Creative Commons license, and indicate if changes were made.

\section{References}

Abass K, Huusko A, Nieminen P, Myllynen P, Pelkonen O, Vahakangas K, Rautio A (2013) Estimation of health risk by using toxicokinetic modelling: a case study of polychlorinated biphenyl PCB153. J Hazard Mater 261:1-10

AMAP (2003) AMAP Assessment 2002: The Influence of Global Change on Contaminant Pathways to, within and from the Arctic. AMAP, Oslo

AMAP (2011) Arctic Pollution 2011. AMAP, Oslo

AMAP (2015) AMAP Assessment 2015: Human Health in the Arctic. AMAP, Oslo

AMAP (2016) AMAP assessment 2015: temporal trends in persistent organic pollutants in the Arctic. Arctic Monitoring and Assessment Programme (AMAP), Oslo

AMAP (2017) Snow, water, ice and permafrost in the Arctic (SWIPA) 2017. Arctic Monitoring and Assessment Programme (AMAP), Oslo, p vii

Armitage JM, Quinn CL, Wania F (2011) Global climate change and contaminants - an overview of opportunities and priorities for modelling the potential implications for long-term human exposure to organic compounds in the Arctic. J Environ Monit 13:1532-1546

Backe C, Larsson P, Agrell C (2002) Spatial and temporal variation of polychlorinated biphenyl (PCB) in precipitation in Southern Sweden. Sci Total Environ 285:117-132

Baldassare R, Nicolle D (1989) Polychlorinated biphenyls'. Can J Ophthalmol 24:248-250

Ballschmiter K, Zell M (1980) Baseline studies of the global pollution. I. Occurrence of organohalogens in pristine European and Antarctic aquatic environments. Int J Environ Anal Chem 8:15-35
Barrie LA, Gregor D, Hargrave B, Lake R, Muir D, Shearer R, Tracey B, Bidleman T (1992) Arctic contaminants: sources, occurrence and pathways. Sci Total Environ 122:1-74

Beyer A, Biziuk M (2009) Environmental fate and global distribution of polychlorinated biphenyls. Rev Environ Contam Toxicol 201:137-158

Bidleman TF (1988) Atmospheric processes: wet and dry deposition of organic-compounds are controlled by their vapor particle partitioning. Environ Sci Technol 22:361-367

Bignert A, Olsson M, Persson W, Jensen S, Zakrisson S, Litzen K et al (1998) Temporal trends of organochlorines in Northern Europe, 1967-1995. Relation to global fractionation, leakage from sediments and international measures. Environ Pollut 99:177-198

Bjerregaard-Olesen C, Long M, Ghisari M, Bech BH, Nohr EA, Uldbjerg $\mathrm{N}$ et al (2017) Temporal trends of lipophilic persistent organic pollutants in serum from danish nulliparous pregnant women 20112013. Environ Sci Pollut Res Int 24:16592-16603

Bogdal C, Muller CE, Buser AM, Wang Z, Scheringer M, Gerecke AC et al (2014) Emissions of polychlorinated biphenyls, polychlorinated dibenzo-p-dioxins, and polychlorinated dibenzofurans during 2010 and 2011 in Zurich, Switzerland. Environ Sci Technol 48:482-490

Bonefeld-Jørgensen EC (2004) The human health effect programme in Greenland, a review. Sci Total Environ 331:215-231

Bonefeld-Jørgensen EC (2010) Biomonitoring in Greenland: human biomarkers of exposure and effects - a short review. Rural Remote Health 10:1362

Bonefeld-Jørgensen EC, Long M (2010) Dioxin-like activity in the blood of Greenlandic Inuit and Danish women: a pilot study. Int $\mathbf{J}$ Circumpolar Health 69:181-194

Boonstra R (2004) Coping with changing northern environments: the role of the stress axis in birds and mammals. Integr Comp Biol 44:95-108

Borgå K, Bidleman TF (2005a) Enantiomer fractions of organic chlorinated pesticides in arctic marine ice fauna, zooplankton, and benthos. Environ Sci Technol 39:3464-3473. https://doi.org/10.1021/ es048055e

Borgå K, Wolkers H, Skaare JU, Hop H, Muir DCG, Gabrielsen GW (2005b) Bioaccumulation of PCBs in Arctic seabirds: influence of dietary exposure and congener biotransformation. Environ Pollut 134:397-409

Borgå K, Saloranta TM, Ruus A (2010) Simulating climate changeinduced alterations in bioaccumulation of organic contaminants in an Arctic marine food web. Environ Toxicol Chem 29:1349-1357

Boucher O, Bastien CH, Saint-Amour D, Dewailly E, Ayotte P, Jacobson JL, Jacobson SW, Muckle G (2010) Prenatal exposure to methylmercury and PCBs affects distinct stages of information processing: an event-related potential study with Inuit children. Neurotoxicology 31 : 373-384

Bowes GW, Jonkel CJ (1972) Polychlorinated biphenyl (PCB) identification in marine Arctic and sub-Arctic food chains. Abstr Pap Am Chem S 164:12-\&

Boyce DG, Lewis MR, Worm B (2010) Global phytoplankton decline over the past century. Nature 466:591-596

Braune BM, Simon M (2003) Dioxins, furans, and non-ortho PCBs in Canadian Arctic seabirds. Environ Sci Technol 37:3071-3077

Braune BM, Donaldson GM, Hobson KA (2001) Contaminant residues in seabird eggs from the Canadian Arctic. Part I. Temporal trends 1975-1998. Environ Pollut 114:39-54

Braune BM, Outridge PM, Fisk AT, Muir DCG, Helm PA, Hobbs K et al (2005) Persistent organic pollutants and mercury in marine biota of the Canadian Arctic: an overview of spatial and temporal trends. Sci Total Environ 351:4-56 
Breivik K, Sweetman A, Pacyna JM, Jones KC (2007) Towards a global historical emission inventory for selected PCB congeners - a mass balance approach 3. An update. Sci Total Environ 377:296-307

Breivik K, Gioia R, Chakraborty P, Zhang G, Jones KC (2011) Are reductions in industrial organic contaminants emissions in rich countries achieved partly by export of toxic wastes? Environ Sci Technol 45:9154-9160

Bright DA, Dushenko WT, Grundy SL, Reimer KJ (1995) Evidence for short-range transport of polychlorinated-biphenyls in the Canadian Arctic using congener signatures of PCBs in soils. Sci Total Environ 160-61:251-263

Brorström-Lundén E, Munthe J, Andersson H, Halsall C, Kallenborn R, Carlsson P et al (2013) Polychlorinated biphenyls (PCB) case study-PCBs in a changing Arctic: understanding their input, transfer and up-take into Arctic biota and humans under climate change. (ArcRisk Deliverable 48). Arctic Monitoring and Assessment Programme (AMAP), Oslo

Bustnes JO, Gabrielsen GW, Verreault J (2010) Climate variability and temporal trends of persistent organic pollutants in the Arctic: a study of glaucous gulls. Environ Sci Technol 44:3155-3161

Bustnes JO, Bardsen BJ, Moe B, Herzke D, Hanssen SA, Sagerup K et al (2017) Temporal variation in circulating concentrations of organochlorine pollutants in a pelagic seabird breeding in the high arctic. Environ Toxicol Chem 36:442-448

Candolin U, Nieminen A, Nyman J (2014) Indirect effects of humaninduced environmental change on offspring production mediated by behavioural responses. Oecologia 174:87-97

Cao Z, Xu F, Covaci A, Wu M, Wang H, Yu G, Wang B, Deng S, Huang J, Wang X (2014) Distribution patterns of brominated, chlorinated, and phosphorus flame retardants with particle size in indoor and outdoor dust and implications for human exposure. Environ Sci Technol 48:8839-8846

Carlsson P, Herzke D, Kallenborn R (2014a) Polychlorinated biphenyls (PCBs), polybrominated diphenyl ethers (PBDEs) and perfluorinated alkylated substances (PFASs) in traditional seafood items from western Greenland. Environ Sci Pollut Res 21: $4741-4750$

Carlsson P, Warner NA, Hallanger IG, Herzke D, Kallenborn R (2014b) Spatial and temporal distribution of chiral pesticides in Calanus spp. from three Arctic fjords. Environ Pollut 192:154-161

Carlsson P, Crosse JD, Halsall C, Evenset A, Heimstad ES, Harju M (2016) Perfluoroalkylated substances (PFASs) and legacy persistent organic pollutants (POPs) in halibut and shrimp from coastal areas in the far north of Norway: small survey of important dietary foodstuffs for coastal communities. Mar Pollut Bull 105(81):87

Carpenter DO (1998) Polychlorinated biphenyls and human health. Int J Occup Med Environ Health 11:291-303

Carpenter DO (2006) Polychlorinated biphenyls (PCBS): routes of exposure and effects on human health. Rev Environ Health 21:1-23

Carrizo D, Gustafsson O (2011a) Distribution and inventories of polychlorinated biphenyls in the polar mixed layer of seven panArctic shelf seas and the interior basins. Environ Sci Technol 45: $1420-1427$

Carrizo D, Gustafsson O (2011b) Pan-Arctic river fluxes of polychlorinated biphenyls. Environ Sci Technol 45:8377-8384

Carroll J, Savinov V, Savinova T, Dahle S, McCrea R, Muir DC (2008) PCBs, PBDEs and pesticides released to the Arctic Ocean by the Russian rivers $\mathrm{Ob}$ and Yenisei. Environ Sci Technol 42:69-74

Cleemann M, Riget F, Paulsen GB, Klungsoyr J, Dietz R (2000) Organochlorines in greenland marine fish, mussels and sediments. Sci Total Environ 245:87-102
Codling G (2012) The geochemical behaviour of organic pollutants in the Arctic and sub-Arctic snowpack. PhD thesis. Lancaster University, UK. https://onesearch.lancaster-university.uk/

Cousins IT, Kong D, Vestergren R (2011a) Reconciling measurement and modelling studies of the sources and fate of perfluorinated carboxylates. Environ Chem 8:339-354

Cousins IT, Kong DG, Vestergren R (2011b) Impact of climate change on exposure to pops for wildlife and humans. In: Climate change and pops: Predicting the impacts:Report of the UNEP/AMAP Expert Group, 21-28

Dallaire R, Dewailly E, Ayotte P, Forget-Dubois N, Jacobson SW, Jacobson JL et al (2013) Exposure to organochlorines and mercury through fish and marine mammal consumption: Associations with growth and duration of gestation among inuit newborns. Environ Int 54:85-91

Derocher AE, Wolkers H, Colborn T, Schlabach M, Larsen TS, Wiig O (2003) Contaminants in Svalbard polar bear samples archived since 1967 and possible population level effects. Sci Total Environ 301: 163-174

Desideri PG, Lepri L, Checchini L, Santianni D (1994) Organic compounds in surface and deep snow. Int J Environ Anal Chem 55:13

Deutch B, Dyerberg J, Pedersen HS, Aschlund E, Hansen JC (2007) Traditional and modern Greenlandic food-dietary composition, nutrients and contaminants. Sci Total Environ 384:106-119

Dewailly E, Nantel A, Weber JP, Meyer F (1989) High levels of PCBs in breast milk of Inuit women from Arctic Quebec. Bull Environ Contam Toxicol 43:641-646

Dewailly E, Ryan JJ, Laliberte C, Bruneau S, Weber JP, Gingras S et al (1994) Exposure of remote maritime populations to coplanar PCBs. Environ Health Perspect 102(Suppl 1):205-209

Diamond ML, Melymuk L, Csiszar SA, Robson M (2010) Estimation of PCB stocks, emissions, and urban fate: will our policies reduce concentrations and exposure? Environ Sci Technol 44:2777-2783

Donaldson SG, Van Oostdam J, Tikhonov C, Feeley M, Armstrong B, Ayotte $P$ et al (2010) Environmental contaminants and human health in the Canadian Arctic. Sci Total Environ 408:5165-5234

Donaldson SG, Curren MS, Adlard B, Provost J, Leech T, Tikhonov C et al (2013) Future human health research directions for the Canadian northern contaminants program. Int J Circumpolar Health 72:23049

Dudarev AA (2012) Dietary exposure to persistent organic pollutants and metals among inuit and Chukchi in Russian Arctic Chukotka. Int J Circumpolar Health 71:18592

Dudarev AA, Konoplev AV, Sandanger TM, Vlasov SV, Miretsky GI, Samsonov DP, Chernik GV, Morshina TN, Pasynkova EM, Pervunina RI, Dorofeev VM, Chaschin MV, Sedenkov DA, Zibarev EV, Kuzmin AV, Abryutina LI, Kimstach VA, Chaschin VP (2004) Blood concentrations of persistent toxic substances in the indigenous communities of the Russian Arctic. Int $\mathrm{J}$ Circumpolar Health 63(Suppl 2):179-182

Dudley JP, Hoberg EP, Jenkins EJ, Parkinson AJ (2015) Climate change in the North American Arctic: a one health perspective. EcoHealth 12:713-725

Eckhardt S, Breivik K, Manø S, Stohl A (2007) Record high peaks in PCB concentrations in the Arctic atmosphere due to long-range transport of biomass burning emissions. Atmos Chem Phys 7:9

Evenset A, Hallanger IG, Tessmann M, Warner N, Ruus A, Borgå K, Gabrielsen GW, Christensen G, Renaud PE (2016) Seasonal variation in accumulation of persistent organic pollutants in an Arctic marine benthic food web. Sci Total Environ 542:108-120

Fang J, Nyberg E, Winnberg U, Bignert A, Bergman A (2015) Spatial and temporal trends of the Stockholm Convention POPs in mothers' milk—a global review. Environ Sci Pollut Res Int 22:8989-9041 
Faroon O, Ruiz P (2015) Polychlorinated biphenyls: new evidence from the last decade. Toxicol Ind Health

Fernandez MF, Sunyer J, Grimalt J, Rebagliato M, Ballester F, Ibarluzea J, Ribas-Fitó N, Tardon A, Fernandez-Patier R, Torrent M, Olea N (2007) The Spanish environment and childhood research network (INMA study). Int J Hyg Environ Health 210:491-493

Fernandez-Gonzalez R, Yebra-Pimentel I, Martinez-Carballo E, SimalGandara J (2015) A critical review about human exposure to polychlorinated dibenzo-p-dioxins (PCDDs), polychlorinated dibenzofurans (PCDFs) and polychlorinated biphenyls (PCBs) through foods. Crit Rev Food Sci Nutr 55:1590-1617

Fisk AT, Hobson KA, Norstrom RJ (2001a) Influence of chemical and biological factors on trophic transfer of persistent organic pollutants in the Northwater Polynya marine food web. Environ Sci Technol 35:732-738

Fisk AT, Stern GA, Hobson KA, Strachan WJ, Loewen MD, Norstrom RJ (2001b) Persistent organic pollutants (POPs) in a small, herbivorous, Arctic marine zooplankton (Calanus hyperboreus): trends from April to July and the influence of lipids and trophic transfer. Mar Pollut Bull 43:93-101

Fisk AT, de Wit CA, Wayland M, Kuzyk ZZ, Burgess N, Letcher R, Braune B, Norstrom R, Blum SP, Sandau C, Lie E, HJS L, Skaare JU, DCG M (2005) An assessment of the toxicological significance of anthropogenic contaminants in Canadian Arctic wildlife. Sci Total Environ 351-352:57-93

Foreid S, Rundberget T, Severinsen T, Wiig O, Skaare JU (2000) Determination of toxaphenes in fish and marine mammals. Chemosphere 41:521-528

Friedman CL, Zhang Y, Selin NE (2014) Climate change and emissions impacts on atmospheric PAH transport to the Arctic. Environ Sci Technol 48:429-437

Garmash O, Hermanson MH, Isaksson E, Schwikowski M, Divine D, Teixeira C, DCG M (2013) Deposition history of polychlorinated biphenyls to the Lomonosovfonna glacier, Svalbard: a 209 congener analysis. Environ Sci Technol 47:12064-12072

Gasic B, MacLeod M, Klanova J, Scheringer M, Ilic P, Lammel G, Pajovic A, Breivik K, Holoubek I, Hungerbühler K (2010) Quantification of sources of PCBs to the atmosphere in urban areas: a comparison of cities in North America, Western Europe and former Yugoslavia. Environ Pollut 158:3230-3235

Gewurtz SB, Laposa R, Gandhi N, Christensen GN, Evenset A, Gregor D, Diamond ML (2006) A comparison of contaminant dynamics in Arctic and temperate fish: a modeling approach. Chemosphere 63: $1328-1341$

Gibson J, Adlard B, Olafsdottir K, Sandanger TM, Odland JO (2016) Levels and trends of contaminants in humans of the arctic. Int $\mathrm{J}$ Circumpolar Health 75:33804

Gobas FAPC, Morrison HA (2000) Bioconcentration and biomagnification in the aquatic environment. In: Boethling RS, Mackay D (eds) Handbook of property estimation methods for chemicals. LEWIS, Florida, pp 189-232

Gomez-Ramirez P, Shore RF, van den Brink NW, van Hattum B, Bustnes JO, Duke G et al (2014) An overview of existing raptor contaminant monitoring activities in Europe. Environ Int 67:12-21

Gouin T, Armitage JM, Cousins IT, Muir DCG, Ng CA, Reid L, Tao S (2013) Influence of global climate change on chemical fate and bioaccumulation: the role of multimedia models. Environ Toxicol Chem 32:20-31

Grannas AM, Bogdal C, Hageman KJ, Halsall C, Harner T, Hung H, Kallenborn R, Klán P, Klánová J, Macdonald RW, Meyer T, Wania F (2013) The role of the global cryosphere in the fate of organic contaminants. Atmos Chem Phys 13:3271-3305
Guglielmo F, Lammel G, Maier-Reimer E (2009) Global environmental cycling of gamma-HCH and DDT in the 1980s - a study using a coupled atmosphere and ocean general circulation model. Chemosphere 76:1509-1517

Guglielmo F, Stemmler I, Lammel G (2012) The impact of organochlorines cycling in the cryosphere on their global distribution and fate1. Sea ice. Environ Pollut 162:475-481

Gustafsson O, Andersson P, Axelman J, Bucheli TD, Komp P, McLachlan MS et al (2005) Observations of the PCB distribution within and in-between ice, snow, ice-rafted debris, ice-interstitial water, and seawater in the Barents Sea marginal ice zone and the North Pole area. Sci Total Environ 342:261-279

Guxens M, Ballester F, Espada M, Fernandez MF, Grimalt JO, Ibarluzea $J$ et al (2012) Cohort profile: the inma-infancia y medio ambiente-(environment and childhood) project. Int $\mathrm{J}$ Epidemiol 41:930-940

Hallanger IG, Ruus A, Warner NA, Herzke D, Evenset A, Schoyen M et al (2011a) Differences between Arctic and Atlantic fjord systems on bioaccumulation of persistent organic pollutants in zooplankton from Svalbard. Sci Total Environ 409:2783-2795

Hallanger IG, Warner NA, Ruus A, Evenset A, Christensen G, Herzke D, Gabrielsen GW, Borgå K (2011b) Seasonality in contaminant accumulation in Arctic marine pelagic food webs using trophic magnification factor as a measure of bioaccumulation. Environ Toxicol Chem 30:1026-1035

Halse AK, Schlabach M, Eckhardt S, Sweetman A, Jones KC, Breivik K (2011) Spatial variability of POPs in European background air. Atmos Chem Phys 11:1549-1564

Hansen JC (1998) The human health programme under AMAP. AMAP Human Health Group, Arctic Monitoring and Assessment Programme. Int J Circumpolar Health 57:280-291

Hansen JC (2000) Environmental contaminants and human health in the Arctic. Toxicol Lett 112-113:119-125

Hansen JC, Reiersen LO, Wilson S (2002) Arctic Monitoring and Assessment Programme (AMAP); strategy and results with focus on the human health assessment under the second phase of AMAP, 1998-2003. Int J Circumpolar Health 61:300-318

Hansen KM, Halsall CJ, Christensen JH (2006) A dynamic model to study the exchange of gas-phase persistent organic pollutants between air and a seasonal snowpack. Environ Sci Technol 40: 2644-2652

Hansen KM, Christensen JH, Brandt J, Frohn LM, Geels C, Skjoth CA, Li Y-F (2008) Modeling short-term variability of alpha-hexachlorocyclohexane in Northern Hemispheric air. J Geophys Res-Atmos 113. https://doi.org/10.1029/2007jd008492

Hansen S, Nieboer E, Odland JO, Wilsgaard T, Veyhe AS, Sandanger TM (2010) Levels of organochlorines and lipids across pregnancy, delivery and postpartum periods in women from Northern Norway. J Environ Monit 12:2128-2137

Hansen KM, Christensen JH, Geels C, Silver JD, Brandt J (2015) Modelling the impact of climate change on the atmospheric transport and the fate of persistent organic pollutants in the Arctic. Atmos Chem Phys 15:6549-6559 https://doi.org/10.5194/acp-15-65492015

Hansson K, Cousins AP, Brorstom-Lunden E, Leppanen S (2006) Atmospheric concentrations in air and deposition fluxes of POPs at Råö and Pallas, trends and seasonal and spatial variations (Reports of the Swedish Environmental Research Institute (IVL)). IVL Swedish Environmental Research Institute, Gothenburg

Haukas M, Berger U, Hop H, Gulliksen B, Gabrielsen GW (2007) Bioaccumulation of per- and polyfluorinated alkyl substances (PFAS) in selected species from the barents sea food web. Environ Pollut 148:360-371 
Heidam NZ, Christensen J, Wahlin P, Skov H (2004) Arctic atmospheric contaminants in NE Greenland: levels, variations, origins, transport, transformations and trends 1990-2001. Sci Total Environ 331:5-28

Hellou J, Warren WG, Payne JF (1993) Organochlorines including polychlorinated biphenyls in muscle, liver, and ovaries of cod, Gadus morhua. Arch Environ Contam Toxicol 25:497-505

Henry TB (2015) Ecotoxicology of polychlorinated biphenyls in fish - a critical review. Crit Rev Toxicol 45:643-661

Herbert BM, Halsall CJ, Villa S, Jones KC, Kallenborn R (2005) Rapid changes in PCB and OC pesticide concentrations in Arctic snow. Environ Sci Technol 39:2998-3005

Herbert BM, Villa S, Halsall CJ (2006) Chemical interactions with snow: understanding the behavior and fate of semi-volatile organic compounds in snow. Ecotoxicol Environ Saf 63:3-16

Hickie BE, Muir DCG, Addison RF, Hoekstra PF (2005) Development and application of bioaccumulation models to assess persistent organic pollutant temporal trends in Arctic ringed seal (Phoca hispida) populations. Sci Total Environ 351:413-426

Hobbs KE, Muir DC, Born EW, Dietz R, Haug T, Metcalfe T et al (2003) Levels and patterns of persistent organochlorines in minke whale (Balaenoptera acutorostrata) stocks from the North Atlantic and European Arctic. Environ Pollut 121:239-252

Hofmann L, Stemmler I, Lammel G (2012) The impact of organochlorines cycling in the cryosphere on global distributions and fate- 2 . Land ice and temporary snow cover. Environ Pollut 162:482-488

Hu D, Hornbuckle KC (2010) Inadvertent polychlorinated biphenyls in commercial paint pigments. Environ Sci Technol 44:2822-2827

Hung H, Kallenborn R, Breivik K, Su Y, Brorström-Lundén E, Olafsdottir K, Thorlacius JM, Leppänen S, Bossi R, Skov H, Manø S, Patton GW, Stern G, Sverko E, Fellin P (2010) Atmospheric monitoring of organic pollutants in the Arctic under the Arctic Monitoring and Assessment Programme (AMAP): 1993 2006. Sci Total Environ 408:2854-2873

Hung H, Katsoyiannis AA, Brorström-Lundén E, Olafsdottir K, Aas W, Breivik K, Bohlin-Nizzetto P, Sigurdsson A, Hakola H, Bossi R, Skov H, Sverko E, Barresi E, Fellin P, Wilson S (2016) Temporal trends of persistent organic pollutants (POPs) in Arctic air: 20 years of monitoring under the Arctic Monitoring and Assessment Programme (AMAP). Persistent Org Pollut POPs Trends Sources Transp Model 217:52-61

Ikonomou MG, Addison RF (2008) Polybrominated diphenyl ethers (PBDEs) in seal populations from eastern and western Canada: an assessment of the processes and factors controlling PBDE distribution in seals. Mar Environ Res 66:225-230

Jensen S, Johnels AG, Olsson M, Otterlind G (1969) DDT and PCB in marine animals from Swedish waters. Nature 224:247-250

Johansen P, Muir D, Asmund G, Riget F (2004) Human exposure to contaminants in the traditional Greenland diet. Sci Total Environ 331:189-206

Jones KC (1988) Determination of polychlorinated biphenyls in human foodstuffs and tissues: suggestions for a selective congener analytical approach. Sci Total Environ 68:141-159

Kalinovich I, Rutter A, Poland JS, Cairns G, Rowe RK (2008) Remediation of PCB contaminated soils in the Canadian Arctic: excavation and surface PRB technology. Sci Total Environ 407: $53-66$

Kallenborn R, Christensen G, Evenset A, Schlabach M, Stohl A (2007) Atmospheric transport of persistent organic pollutants (POPs) to Bjørnøya (Bear island). J Environ Monit 9:1082-1091

Kallenborn R, Halsall C, Dellong M, Carlsson P (2012) The influence of climate change on the global distribution and fate processes of anthropogenic persistent organic pollutants. J Environ Monit 14:2854-2869
Kelly R, Chipman ML, Higuera PE, Stefanova I, Brubaker LB, Hu FS (2013) Recent burning of boreal forests exceeds fire regime limits of the past 10,000 years. Proc Natl Acad Sci U S A 110:13055-13060

Kimbrough RD, Jensen AA (1989) Halogenated biphenyls, terphenyls, naphthalenes, dibenzodioxins and related products. Elsevier

Kleivane L, Severinsen T, Skaare JU (2000) Biological transport and mammal to mammal transfer of organochlorines in Arctic fauna. Mar Environ Res 49:343-357

Klopov V, Odland JO, Burkow IC (1998) Persistent organic pollutants in maternal blood plasma and breast milk from Russian Arctic populations. Int J Circumpolar Health 57:239-248

Kong D, MacLeod M, Cousins IT (2014) Modelling the influence of climate change on the chemical concentrations in the Baltic Sea region with the POPCYCLING-Baltic model. Chemosphere 110: $31-40$

Korrick SA, Sagiv SK (2008) Polychlorinated biphenyls, organochlorine pesticides and neurodevelopment. Curr Opin Pediatr 20:198-204

Kraemer LD, Berner JE, Furgal CM (2005) The potential impact of climate on human exposure to contaminants in the Arctic. Int $\mathrm{J}$ Circumpolar Health 64:498-508

Kruger T, Long M, Ghisari M, Bonefeld-Jorgensen EC (2012) The combined effect of persistent organic pollutants in the serum pop mixture in greenlandic inuit: xenoestrogenic, xenoandrogenic and dioxinlike transactivities. Biomarkers 17:692-705

Kucklick JR, Struntz WADJ, Becker PR, York GW, O'Hara TM, Bohonowych JE (2002) Persistent organochlorine pollutants in ringed seals and polar bears collected from northern Alaska. Sci Total Environ 287:45-59

Lamon L, Von Waldow H, Macleod M, Scheringer M, Marcomini A, Hungerbuhler K (2009) Modeling the global levels and distribution of polychlorinated biphenyls in air under a climate change scenario. Environ Sci Technol 43:5818-5824

Lang V (1992) Polychlorinated biphenyls in the environment. J Chromatogr 595:1-43

Lei Y, Wania F (2004) Is rain or snow a more efficient scavenger of organic chemicals? Atmos Environ 38:3557-3571

Letcher RJ, Bustnes JO, Dietz R, Jenssen BM, Jørgensen EH, Sonne C, Verreault J, Vijayan MM, Gabrielsen GW (2010) Exposure and effects assessment of persistent organohalogen contaminants in Arctic wildlife and fish. Sci Total Environ 408:2995-3043

Linares V, Perello G, Nadal M, Gomez-Catalan J, Llobet JM, Domingo JL (2010) Environmental versus dietary exposure to POPs and metals: a probabilistic assessment of human health risks. J Environ Monit 12:681-688

Llop S, Murcia M, Alvarez-Pedrerol M, Grimalt JO, Santa-Marina L, Julvez J, Goñi-Irigoyen F, Espada M, Ballester F, Rebagliato M, Lopez-Espinosa MJ (2017) Association between exposure to organochlorine compounds and maternal thyroid status: role of the iodothyronine deiodinase 1 gene. Environ Int 104:83-90

Lorber M (2008) Exposure of Americans to polybrominated diphenyl ethers. J Expo Sci Environ Epidemiol 18:2-19

Ma JM, Hung HL, Tian C, Kallenborn R (2011) Revolatilization of persistent organic pollutants in the Arctic induced by climate change. Nat Clim Chang 1:255-260

Macdonald RW, Bewers JM (1996) Contaminants in the Arctic marine environment: priorities for protection. ICES J Mar Sci 53:537-563

Macdonald RW, Mackay D, Li YF, Hickie B (2003) How will global climate change affect risks from long-range transport of persistent organic pollutants? Hum Ecol Risk Assess 9:643-660

Macdonald RW, Harner T, Fyfe J (2005) Recent climate change in the arctic and its impact on contaminant pathways and interpretation of temporal trend data. Sci Total Environ 342:5-86 
MacLeod M, von Waldow H, Tay P, Armitage JM, Wöhrnschimmel H, Riley WJ, TE MK, Hungerbuhler K (2011) Betr global-a geographically-explicit global-scale multimedia contaminant fate model. Environ Pollut 159:1442-1445

MacLeod M, Breitholtz M, Cousins IT, de Wit CA, Persson LM, Ruden C et al (2014) Identifying chemicals that are planetary boundary threats. Environ Sci Technol 48:11057-11063

Magulova K, Priceputu A (2016) Global monitoring plan for persistent organic pollutants (POPs) under the Stockholm convention: triggering, streamlining and catalyzing global POPs monitoring. Persistent Org Pollut POPs Trends Sources Transp Model 217:82-84

Malmquist C, Bindler R, Renberg I, van Bavel B, Karlsson E, Anderson NJ, Tysklind M (2003) Time trends of selected persistent organic pollutants in lake sediments from Greenland. Environ Sci Technol 37:4319-4324

McKinney JD, Waller CL (1994) Polychlorinated biphenyls as hormonally active structural analogues. Environ Health Perspect 102:290-297

McKinney MA, Letcher RJ, Aars J, Born EW, Branigan M, Dietz R et al (2011) Flame retardants and legacy contaminants in polar bears from alaska, canada, east greenland and svalbard, 2005-2008. Environ Int 37:365-374

Meijer SN, Ockenden WA, Sweetman A, Breivik K, Grimalt JO, Jones KC (2003) Global distribution and budget of PCBs and HCB in background surface soils: implications for sources and environmental processes. Environ Sci Technol 37:667-672

Meyer T, Lei YD, Muradi I, Wania F (2009) Organic contaminant release from melting snow. 2. Influence of snow pack and melt characteristics. Environ Sci Technol 43:663-668

Morales E, Gascon M, Martinez D, Casas M, Ballester F, RodriguezBernal CL et al (2013) Associations between blood persistent organic pollutants and 25-hydroxyvitamin $\mathrm{d} 3$ in pregnancy. Environ Int 57-58:34-41

Muir DCG, de Wit CA (2010) Trends of legacy and new persistent organic pollutants in the circumpolar arctic: overview, conclusions, and recommendations. Sci Total Environ 408:3044-3051

Muir DC, Wagemann R, Hargrave BT, Thomas DJ, Peakall DB, Norstrom RJ (1992) Arctic marine ecosystem contamination. Sci Total Environ 122:75-134

Nieminen P, Lehtiniemi H, Huusko A, Vahakangas K, Rautio A (2013a) Polychlorinated biphenyls (PCBS) in relation to secondary sex ratioa systematic review of published studies. Chemosphere 91:131-138

Nieminen P, Lehyiniemi H, Vähäkangas K, Huusko A, Rautio A (2013b) Summarizing the reported findings between quantitative exposure and outcome variables from epidemiologic studies in a consistent form: the effect of exposure to polychlorinated biphenyls (PCBs) on birth weight as an example. Epidemiol Biostat Public Health 10:15

Norstrom RJ, Belikov SE, Born EW, Garner GW, Malone B, Olpinski S, Ramsay MA, Schliebe S, Stirling I, Stishov MS, Taylor MK, Wiig O (1998) Chlorinated hydrocarbon contaminants in polar bears from Eastern Russia, North America, Greenland, and Svalbard: biomonitoring of Arctic pollution. Arch Environ Contam Toxicol 35:354-367

Nost TH, Sandanger TM, Nieboer E, Odland JO, Breivik K (2017) The impacts of emission trends of pops on human concentration dynamics: Lessons learned from a longitudinal study in norway (19792007). Int J Hyg Environ Health 220:776-781

Nøst TH, Breivik K, Fuskevag OM, Nieboer E, Odland JO, Sandanger TM (2013) Persistent organic pollutants in Norwegian men from 1979 to 2007: intraindividual changes, age-period-cohort effects, and model predictions. Environ Health Perspect 121:1292-1298
Octaviani M, Stemmler I, Lammel G, Graf HF (2015) Atmospheric transport of persistent organic pollutants to and from the arctic under present-day and future climate. Environ Sci Technol 49:3593-3602

Odland JO, Nieboer E (2012) Human biomonitoring in the Arctic. Special challenges in a sparsely populated area. Int J Hyg Environ Health 215:159-167

Olsen MS, Callaghan TV, Reist JD, Reiersen LO, Dahl-Jensen D, Granskog MA, Goodison B, Hovelsrud GK, Johansson M, Kallenborn R, Key J, Klepikov A, Meier W, Overland JE, Prowse TD, Sharp M, Vincent WF, Walsh J (2011) The changing Arctic cryosphere and likely consequences: an overview. Ambio 40:111-118

Olsson M, Bignert A, Eckhell J, J P (2010) Comparison of temporal trends (1940s-1990s) of DDT and PCB in Baltic sediment and biota in relation to eutrophication. Ambio 29:7

Parkinson AJ, Berner J (2009) Climate change and impacts on human health in the Arctic: an international workshop on emerging threats and the response of Arctic communities to climate change. Int $\mathrm{J}$ Circumpolar Health 68:84-91

Pavlova PA, Schmid P, Bogdal C, Steinlin C, Jenk TM, Schwikowski M (2014) Polychlorinated biphenyls in glaciers. 1. Deposition history from an alpine ice core. Environ Sci Technol 48:7842-7848

Peakall DB (1972) Polychlorinated biphenyls: occurrence and biological effects. Residue Rev 44:1-21

Pedersen H, Kallenborn R, Ottesen RT, Gabrielsen GW, Schrum C, Evenset A, Ruus A, Benjaminsen H, Sagerup K, Christensen G, Eggen O, Carlsson P, Johansson-Karlsson E, Polder A, Lundkvist Q (2011) PCBs on Svalbard. Norwegian Environment Agency and Governor of Svalbard, Longyearbyen

Pedro S, Boba C, Dietz R, Sonne C, Rosing-Asvid A, Hansen M et al (2017a) Blubber-depth distribution and bioaccumulation of pcbs and organochlorine pesticides in Arctic-invading killer whales. Sci Total Environ 601-602:237-246

Pedro S, Fisk AT, Tomy GT, Ferguson SH, Hussey NE, Kessel ST et al (2017b) Mercury and persistent organic pollutants in native and invading forage species of the canadian arctic: Consequences for food web dynamics. Environ Pollut 229:229-240

Pucko M, Stern GA, Macdonald RW, Barber DG (2010) Alpha- and gamma-hexachlorocyclohexane measurements in the brine fraction of sea ice in the Canadian high Arctic using a sump-hole technique. Environ Sci Technol 44:9258-9264

Pucko M, Stern GA, Macdonald RW, Jantunen LM, Bidleman TF, Wong $F$ et al (2015) The delivery of organic contaminants to the Arctic food web: why sea ice matters. Sci Total Environ 506-507:444-452

Rawn DF, Lockhart WL, Wilkinson P, Savoie DA, Rosenberg GB, Muir DC (2001) Historical contamination of Yukon lake sediments by PCBs and organochlorine pesticides: influence of local sources and watershed characteristics. Sci Total Environ 280:17-37

Renaud P, Berge J, Varpe Ø, Lønne O, Nahrgang J, Ottesen C, Hallanger I (2012) Is the poleward expansion by Atlantic cod and haddock threatening native polar cod, Boreogadus saida? Polar Biol 35:401-412

Riget F, Dietz R, Vorkamp K, Johansen P, Muir D (2004) Levels and spatial and temporal trends of contaminants in Greenland biota: an updated review. Sci Total Environ 331:29-52

Riget F, Bignert A, Braune B, Stow J, Wilson S (2010) Temporal trends of legacy POPs in Arctic biota, an update. Sci Total Environ 408:2874 2884

Riget F, Vorkamp K, Hobson KA, Muir DC, Dietz R (2013) Temporal trends of selected POPs and the potential influence of climate variability in a Greenland ringed seal population. Environ Sci Processes Impacts 15:1706-1716

Ritter R, Scheringer M, MacLeod M, Moeckel C, Jones KC, Hungerbuhler K (2011) Intrinsic human elimination half-lives of 
polychlorinated biphenyls derived from the temporal evolution of cross-sectional biomonitoring data from the United Kingdom. Environ Health Perspect 119:225-231

Ross G (2004) The public health implications of polychlorinated biphenyls (PCBs) in the environment. Ecotoxicol Environ Saf 59:275-291

Ryan JJ, Rawn DF (2014) Polychlorinated dioxins, furans (PCDD/Fs), and polychlorinated biphenyls (PCBs) and their trends in Canadian human milk from 1992 to 2005. Chemosphere 102:76-86

Ryan MJ, Stern GA, Kidd KA, Croft MV, Gewurtz S, Diamond M et al (2013) Biotic interactions in temporal trends (1992-2010) of organochlorine contaminants in the aquatic food web of lake Laberge, Yukon territory. Sci Total Environ 443:80-92

Safe SH (1994) Polychlorinated biphenyls (PCBs): environmental impact, biochemical and toxic responses, and implications for risk assessment. Crit Rev Toxicol 24:87-149

Sagerup K, Larsen HJ, Skaare JU, Johansen GM, Gabrielsen GW (2009) The toxic effects of multiple persistent organic pollutant exposures on the post-hatch immunity maturation of glaucous gulls. J Toxicol Environ Health A 72:870-883

Schaebel LK, Bonefeld-Jorgensen EC, Vestergaard H, Andersen S (2017) The influence of persistent organic pollutants in the traditional inuit diet on markers of inflammation. PLoS One 12:e177781

Semazzi F (2003) Air quality research: perspective from climate change modelling research. Environ Int 29:253-261

Sharma S (2010) Assessing diet and lifestyle in the Canadian Arctic Inuit and Inuvialuit to inform a nutrition and physical activity intervention programme. J Hum Nutr Diet 23:5-17

Singh K, Chan HM (2017) Persistent organic pollutants and diabetes among inuit in the Canadian Arctic. Environ Int 101:183-189

Smith KEC, McLachlan MS (2006) Concentrations and partitioning of polychlorinated biphenyls in the surface waters of the southern Baltic Sea — seasonal effects. Environ Toxicol Chem 25:2569-2575

Sobek A, Gustafsson O (2014) Deep water masses and sediments are main compartments for polychlorinated biphenyls in the Arctic Ocean. Environ Sci Technol 48:6719-6725

Stemmler I, Lammel G (2012) Long-term trends of continental-scale PCB patterns studied using a global atmosphere-ocean general circulation model. Environ Sci Pollut Res Int 19:1971-1980

Stocker J, Scheringer M, Wegmann F, Hungerbühler K (2007) Modeling the effect of snow and ice on the global environmental fate and longrange transport potential of semivolatile organic compounds. Environ Sci Technol 41:6192-6198

Sturludottir E, Gunnlaugsdottir H, Jorundsdottir HO, Magnusdottir EV, Olafsdottir K, Stefansson G (2014) Temporal trends of contaminants in cod from icelandic waters. Sci Total Environ 476-477:181-188

Tanabe S, Mori T, Tatsukawa R, Miyazaki N (1983) Global pollution of marine mammals by PCBs, DDTs and HCHs (BHCs). Chemosphere 12:1269-1275

Tartu S, Angelier F, Herzke D, Moe B, Bech C, Gabrielsen GW, Bustnes JO, Chastel O (2014) The stress of being contaminated? Adrenocortical function and reproduction in relation to persistent organic pollutants in female black legged kittiwakes. Sci Total Environ 476-477:553-560

Tartu S, Angelier F, Bustnes JO, Moe B, Hanssen SA, Herzke D, Gabrielsen GW, Verboven N, Verreault J, Labadie P, Budzinski H, Wingfield JC, Chastel O (2015) Polychlorinated biphenyl exposure and corticosterone levels in seven polar seabird species. Environ Pollut 197:173-180

Toft G (2014) Persistent organochlorine pollutants and human reproductive health. Dan Med J 61:B4967

Tørseth K, Aas W, Breivik K, Fjæraa AM, Fiebig M, Hjellbrekke AG et al (2012) Introduction to the European Monitoring and Evaluation
Programme (EMEP) and observed atmospheric composition change during 1972-2009. Atmos Chem Phys 12:35

Turyk M, Anderson H, Knobeloch L, Imm P, Persky V (2009) Organochlorine exposure and incidence of diabetes in a cohort of great lakes sport fish consumers. Environ Health Perspect 117:1076-1082

UNEP/AMAP (2011) Climate change and POPs: predicting the impacts. 62p. Report of the UNEP/AMAP Expert Group Secretariat of the Stockholm Convention, Geneva

Valera B, Ayotte P, Poirier P, Dewailly E (2013a) Associations between plasma persistent organic pollutant levels and blood pressure in inuit adults from nunavik. Environ Int 59:282-289

Valera B, Jorgensen ME, Jeppesen C, Bjerregaard P (2013b) Exposure to persistent organic pollutants and risk of hypertension among inuit from greenland. Environ Res 122:65-73

Van Oostdam JC, Dewailly E, Gilman A, Hansen JC, Odland JO, Chashchin V et al (2004) Circumpolar maternal blood contaminant survey, 1994-1997 organochlorine compounds. Sci Total Environ 330:55-70

Vecchiato M, Zambon S, Argiriadis E, Barbante C, Gambaro A, Piazza R (2015) Polychlorinated biphenyls (PCBs) and polybrominated diphenyl ethers (PBDEs) in Antarctic ice-free areas: influence of local sources on lakes and soils. Microchem J 120:26-33

Verreault J, Muir DC, Norstrom RJ, Stirling I, Fisk AT, Gabrielsen GW et al (2005) Chlorinated hydrocarbon contaminants and metabolites in polar bears (Ursus maritimus) from Alaska, Canada, East Greenland, and Svalbard: 1996-2002. Sci Total Environ 351-352: 369-390

Verreault J, Letcher RJ, Ropstad E, Dahl E, Gabrielsen GW (2006) Organohalogen contaminants and reproductive hormones in incubating glaucous gulls (Larus hyperboreus) from the Norwegian Arctic. Environ Toxicol Chem 25:2990-2996

Veyhe AS, Hofoss D, Hansen S, Thomassen Y, Sandanger TM, Odland JO et al (2015) The northern norway mother-and-child contaminant cohort (misa) study: Pca analyses of environmental contaminants in maternal sera and dietary intake in early pregnancy. Int J Hyg Environ Health 218:254-264

Vijayan MM, Aluru N, Maule AG, Jørgensen EH (2006) Fasting augments PCB impact on liver metabolism in anadromous Arctic char. Toxicol Sci 91:431-439

Villa S, Migliorati S, Monti GS, Holoubek I, Vighi M (2017) Risk of POP mixtures on the Arctic food chain. Environ Toxicol Chem 36:11811192

Vorkamp K (2016) An overlooked environmental issue? A review of the inadvertent formation of PCB-11 and other PCB congeners and their occurrence in consumer products and in the environment. Sci Total Environ 541:1463-1476

Vorkamp K, Rigét FF (2014) A review of new and current-use contaminants in the Arctic environment: Evidence of long-range transport and indications of bioaccumulation. Chemosphere 111:379-395. https://doi.org/10.1016/j.chemosphere.2014.04.019

Walters DM, Jardine TD, Cade BS, Kidd KA, Muir DC, Leipzig-Scott P (2016) Trophic magnification of organic chemicals: A global synthesis. Environ Sci Technol 50:4650-4658

Wania F, Mackay D (1993) Global fractionation and cold condensation of low volatility organochlorine compounds in polar-regions. Ambio 22:10-18

Wania F, Mackay D (1995) A global distribution model for persistent organic-chemicals. Sci Total Environ 160-61:211-232

Wania F, Mackay D (1996) Tracking the distribution of persistent organic pollutants. Environ Sci Technol 30:A390-A396

Winton M (2006) Amplified arctic climate change: what does surface albedo feedback have to do with it? Geophys Res Lett 33 
Wöhrnschimmel H, MacLeod M, Hungerbuhler K (2013) Emissions, fate and transport of persistent organic pollutants to the Arctic in a changing global climate. Environ Sci Technol 47:2323-2330

Wolkers H, van Bavel B, Ericson I, Skoglund E, Kovacs KM, Lydersen C (2006) Congener-specific accumulation and patterns of chlorinated and brominated contaminants in adult male walruses from Svalbard, Norway: indications for individual-specific prey selection. Sci Total Environ 370:70-79
Xu W, Wang X, Cai Z (2013) Analytical chemistry of the persistent organic pollutants identified in the Stockholm Convention: a review. Anal Chim Acta 790:1-13

Zitko V, Choi PM (1972) PCB and $p, p^{\prime}$-DDE in eggs of cormorants, gulls, and ducks from the Bay of Fundy, Canada. Bull Environ Contam Toxicol 7:63-64

\section{Affiliations}

Pernilla Carlsson ${ }^{1}$ (D) $\cdot$ Knut Breivik ${ }^{2} \cdot$ Eva Brorström-Lundén $^{3} \cdot$ lan Cousins ${ }^{4} \cdot$ Jesper Christensen $^{5} \cdot$ Joan O. Grimalt $^{6}$. Crispin Halsall ${ }^{7}$. Roland Kallenborn ${ }^{8,9} \cdot$ Khaled Abass $^{10,11} \cdot$ Gerhard Lammel $^{12,13}$. John Munthe ${ }^{3}$.

Matthew MacLeod ${ }^{4}$. Jon Øyvind Odland ${ }^{14}$. Janet Pawlak ${ }^{15}$. Arja Rautio ${ }^{11} \cdot$ Lars-Otto Reiersen $^{15} \cdot$ Martin Schlabach $^{2}$. Irene Stemmler ${ }^{12,16} \cdot$ Simon Wilson ${ }^{15} \cdot$ Henry Wöhrnschimmel ${ }^{17,18}$

1 Norwegian Institute for Water Research (NIVA), 0349 Oslo, Norway

2 NILU - Norwegian Institute for Air Research, 2027 Kjeller, Norway

3 IVL Swedish Environment Research Institute, 411

33 Göteborg, Sweden

4 Department of Environmental Science and Analytical Chemistry (ACES), Stockholm University, 11418 Stockholm, Sweden

5 Department of Bioscience, Arctic Research Centre, Aarhus University, 4000 Roskilde, Denmark

6 Institute of Environmental Assessment and Water Research (IDÆA), Spanish Council for Scientific Research (CSIC), 0834 Barcelona, Spain

7 Lancaster Environment Centre, Lancaster University, Lancaster LA1 4YQ, UK

8 Faculty of Chemistry, Biotechnology and Food Sciences (KBM), Norwegian University of Life Sciences (NMBU), Christian Magnus Falsen Veg 1, 1432 Ås, Norway

9 Department of Arctic Technology (AT), University Centre in Svalbard (UNIS), 9171 Longyearbyen, Svalbard, Norway
10 Department of Pesticides, Menoufia University, P.O. Box 32511, Shebeen El-Kom, Egypt

11 Arctic Health, Faculty of Medicine, University of Oulu, 90014 Oulu, Finland

12 Max Planck Institute for Chemistry, 55128 Mainz, Germany

13 Research Centre for Toxic Compounds in the Environment, Masaryk University, 62500 Brno, Czech Republic

14 Department of Community Medicine, UiT - The Arctic University of Norway, 9037 Tromsø, Norway

15 Arctic Monitoring and Assessment Programme (AMAP), AMAP Secretariat, Gaustadalléen 21, 0349 Oslo, Norway

16 Max Planck Institute for Meteorology, 20146 Hamburg, Germany

17 Department of Chemistry and Applied Biosciences, Institute of Chemical and Bioengineering, ETH Zürich, 8092 Zürich, Switzerland

18 Swiss Federal Office for the Environment, Worblentalstrasse 68, 3063 Ittigen, Switzerland 